\title{
Signaling Control of Mucociliary Epithelia: Stem Cells, Cell Fates, and the Plasticity of Cell Identity in Development and Disease
}

\author{
Peter Walentek ${ }^{a, b}$ \\ aRenal Division, Department of Medicine, University Hospital Freiburg, Faculty of Medicine, University of Freiburg,

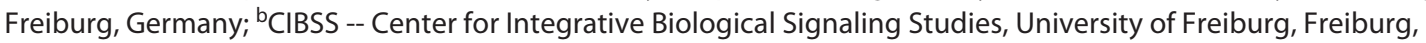 \\ Germany
}

\section{Keywords}

BMP · Bronchial cells; Notch; Wnt; Xenopus

\begin{abstract}
Mucociliary epithelia are composed of multiciliated, secretory, and stem cells and line various organs in vertebrates such as the respiratory tract. By means of mucociliary clearance, those epithelia provide a first line of defense against inhaled particles and pathogens. Mucociliary clearance relies on the correct composition of cell types, that is, the proper balance of ciliated and secretory cells. A failure to generate and to maintain correct cell type composition and function results in impaired clearance and high risk to infections, such as in congenital diseases (e.g., ciliopathies) as well as in acquired diseases, including asthma, chronic obstructive pulmonary disease (COPD), and idiopathic pulmonary fibrosis (IPF). While it remains incompletely resolved how precisely cell types are specified and maintained in development and disease, many studies have revealed important mechanisms regarding the signaling control in mucociliary cell types in various species. Those studies not only provided insights into the signaling contribution to organ development and regeneration but also highlighted the remarkable plasticity of cell identity encountered in mucociliary maintenance, including frequent trans-differentiation events during homeostasis and specifically in disease. This review will
\end{abstract}

summarize major findings and provide perspectives regarding the future of mucociliary research and the treatment of chronic airway diseases associated with tissue remodeling.

(c) 2021 S. Karger AG, Base

\section{The Importance of Understanding the Biology of Mucociliary Epithelia}

A relatively small number of extremely conserved cellcell signaling pathways is able to regulate embryonic development, adult tissue homeostasis, regeneration, and tissue remodeling associated with various diseases [Perrimon et al., 2012; Sanz-Ezquerro et al., 2017]. Those pathways are being reiteratively employed and have to be precisely controlled to elicit tissue- and context-dependent effects. Defective signaling regulation is a common reason for pathogenic physiological and morphological changes. The complexity of biological signaling regulation, the combinatorial interplay between multiple pathways, and the almost unlimited possibilities of dysregulation are making it hard to establish unambiguous links between a given change in signaling and a specific phenotype [Weng et al., 1999].

In addition to congenital defects caused by mutations in important developmental genes, many diseases develop only postnatally or during adulthood. These diseases 
can have predominantly genetic causes, but more often they are promoted by environmental factors in combination with an unfavorable genetic disposition [Renz et al., 2011; Sears and Genuis, 2012]. With the advent of largescale "big data" studies of individuals and populations, we are just starting to elucidate the genetic basis of predispositions to various diseases by whole-exome and genome studies [Naylor and Chen, 2010; Alyass et al., 2015]. We also learn more and more about the chemical and biological basis of various environmental factors with pathogenic potential. Nevertheless, it remains difficult to draw a clear connection between a common genetic variation, the presence of a common environmental factor, and the manifestation of a disease in an individual patient.

Even in cases where the predominant cause can be established, for example, tobacco use and airway diseases, understanding the cause is very different from understanding the pathophysiological mechanism [Graff et al., 2012; van Rijt et al., 2012; Heijink et al., 2013; Ballweg et al., 2014; Schamberger et al., 2014, 2015; Zhang et al., 2014; Wang et al., 2018; Zuo et al., 2019]. Nevertheless, such a level of understanding is necessary for effective prevention, early diagnosis, and especially for the establishment of successful therapies. This problem is further amplified by the facts that patients often come to the clinic only when a chronic disease is already severely impacting on their quality of life and that a definitive diagnosis requires interdisciplinary teams or specialized analytics only available in major clinics and centers. This can lead to a delayed diagnosis, sometimes years after the disease onset [Smith, 2015; Hoyer et al., 2019]. At this point it is even harder to establish what has initially caused a disease and which changes occurred through chronic inflammation, tissue remodeling, and other secondary causes.

It is therefore extremely important to investigate not only defective patient tissue but also to gain insights into the principal functions of genes and signaling pathways from normal development, animal models, and in vitro studies, employing simplified as well as organoid tissue cultures. Such studies have greatly improved our understanding of mucociliary epithelial biology over the years and have shed light onto some of the possible pathophysiological mechanisms that contribute to mucociliary dysfunction, especially relating to chronic airway diseases.

The following sections will review some important findings from basic as well as clinical research on the roles of key signaling pathways in mucociliary development and airway diseases, will summarize emerging concepts, and will highlight open questions in the field.

Mucociliary Signaling

\section{Mucociliary Cell Types, Their Functions, and Associated Diseases}

Mucociliary epithelia line a wide variety of organs in animals, including the epidermis, the female reproductive tract, and the airways. They usually contain stem or progenitor cells, which reside beneath the epithelial layer or at the base of the epithelium and are in contact with the basement membrane; hence, they were named basal cells (BCs) (Fig. 1) [Rock et al., 2009, 2010; Zuo et al., 2015; Haas et al., 2019]. BCs can give rise to all other mucociliary cell types. Their correct regulation, proliferation, and differentiation is of utmost importance for generating and maintaining correct cell type composition and function of the epithelium. Dysregulated BC behavior is found in various diseases affecting airway function, including basal cell hyperplasia, and can lead to a lack of differentiated cells and to alterations in epithelial morphology [Rock et al., 2010; Hogan et al., 2014].

The precise mucociliary cell type composition varies between different organisms and organs. Nevertheless, all types of mucociliary epithelia consist of multiciliated cells (MCCs) as well as one or more secretory cell type(s) (Fig. 1a-d) that provide mucus.

MCCs are highly specialized and form over 100 motile cilia that project from the apical surface and that beat in a metachronal-synchronized fashion to produce directional extracellular fluid flow over the epithelium [Brooks and Wallingford, 2014; Meunier and Azimzadeh, 2016; Walentek et al., 2017]. Depending on the organ, ciliary beating and mucociliary fluid flow can be employed for locomotion, to circulate water for oxygenation, or for directional transport of mucus, oocytes, symbionts, and pathogens. Defects affecting MCCs or motile cilia lead to breakdown of fluid flow and of mucociliary clearance [Tilley et al., 2015]. Consequently, diseases affecting cilia, collectively termed ciliopathies, frequently include respiratory manifestations, increased susceptibility to airway infections, and subfertility in females through increased rates of tubular pregnancies [Ibañez-Tallon et al., 2003; Roy, 2009; Zariwala et al., 2011; Mitchison and Valente, 2017].

Cells secreting mucin glycoproteins, for example goblet cells, are another essential part of mucociliary epithelia. Mucins are long, gel-forming proteins that form a mobile layer which is transported by ciliary motion [Williams et al., 2006; Corfield, 2015]. Due to the gel-like properties of mucus, it serves as a barrier against pathogen entry and the accumulation of harmful particles [Zanin et al., 2016; Wagner et al., 2018]. Mucus traps and facilitates removal

Cells Tissues Organs 2022;211:736-753 737 
Fig. 1. Mucociliary cell types and epithelial cell type compositions. a Schematic representation of cell types in the mammalian trachea. Basal cells (BCs), multiciliated cells (MCCs), and club cells are abundant, while ionocytes and goblet cells are rare. b Schematic representation of cell types in the mammalian submucosal glands. $\mathrm{Mu}$ cous cells are very abundant, while BCs, MCCs, and ionocytes are missing. Additionally, myoepithelial cells function as stem cells. c Schematic representation of cell types in the mammalian bronchioles. MCCs and club cells are abundant, and pulmonary neuroendocrine cells (PNECs) are found in clusters. BCs, ionocytes, and goblet cells are less abundant than in the trachea. d Schematic representation of cell types in the Xenopus embryonic mucociliary epidermis. Basal cells are located in the deep cell layer. MCCs, ionocytes, and small secretory cells (SSCs) are present in equal proportions, while goblet cells are more abundant. e Key to cell types and commonly used cell type markers.
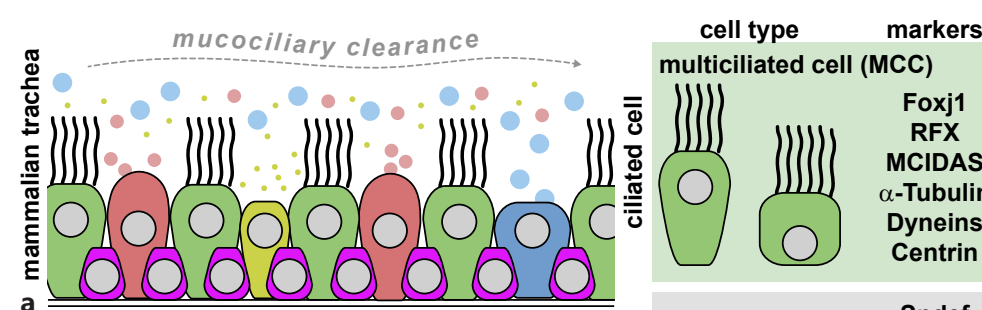

multiciliated cell (MCC)

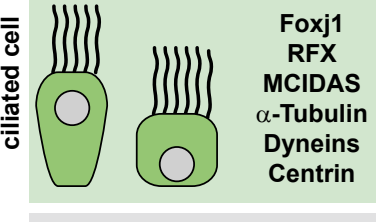

Foxj1

RFX

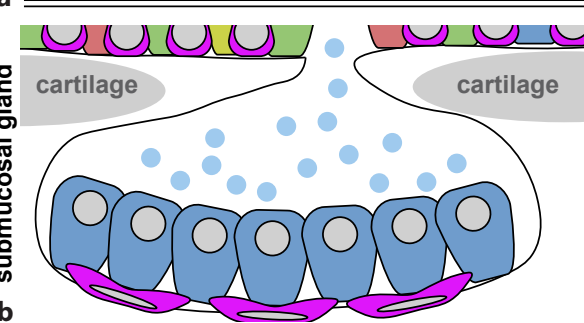

b

goblet/mucous cell Spdef
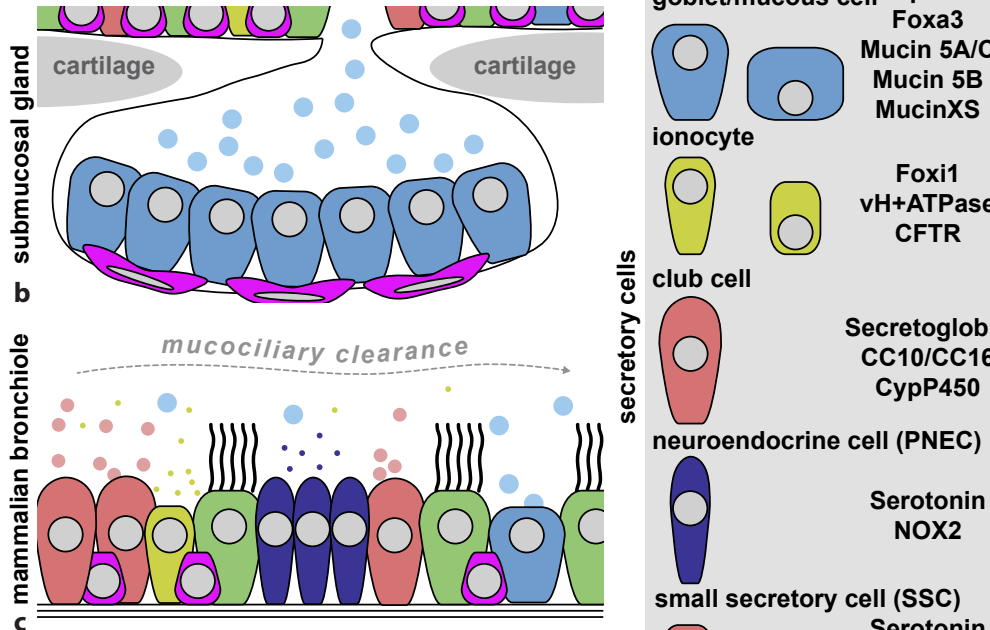

Foxi1
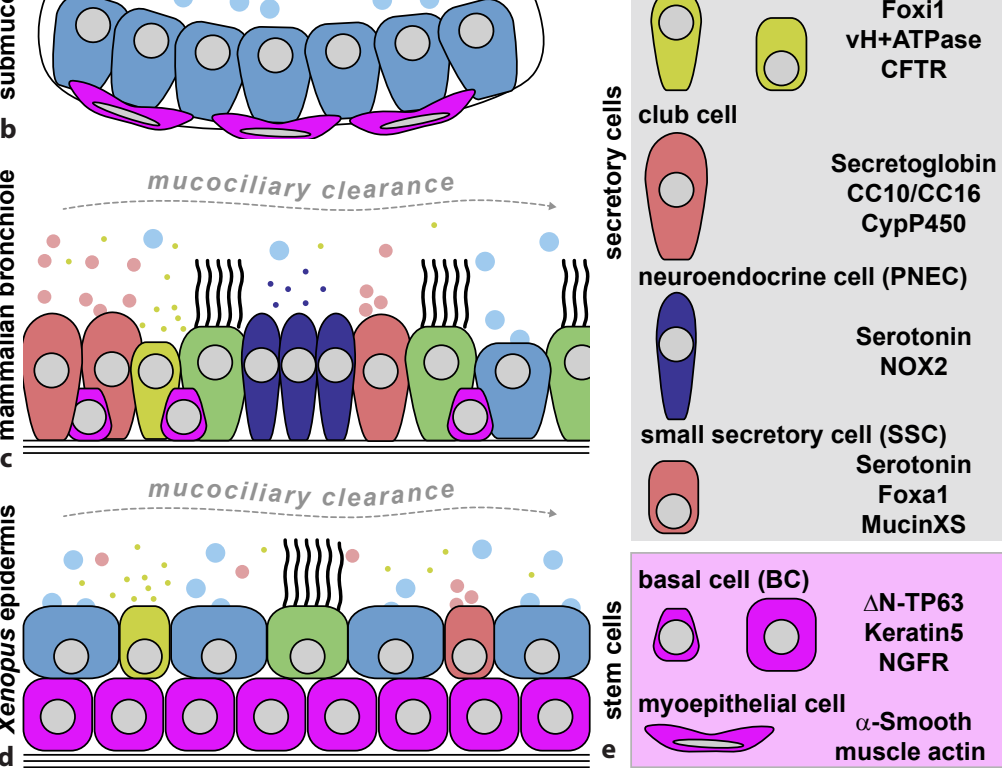

of pathogens and generates spatial distance to the epithelial cell surface. Mucus composition changes in response to inflammation in the mammalian airways [Fahy and Dickey, 2010]. This alters mucus structure and properties to protect the organism from pathogens. On the other hand, excessive secretion of mucus in conditions such as goblet cell hyperplasia is also a feature of chronic lung diseases, including chronic obstructive pulmonary disease (COPD), asthma, or idiopathic pulmonary fibrosis (IPF) [Fahy and Dickey, 2010; Hogan et al., 2014]. In these conditions, increased mucin secretion contributes to the pathology by means of impaired airway clearance, obstruction, and enhanced pathogen accumulation.

Additional secretory cells can exist in mucociliary epithelia that regulate ion balance, secrete substances, or modulate the behavior of other cells.

Ionocytes are enriched for the transmembrane proton pump $\mathrm{vH}^{+} \mathrm{ATPase}$, encoded by ATP6-family genes. De- pending on the ionocyte subtype ( $\alpha$ or $\beta$ ), localization of $\mathrm{vH}^{+} \mathrm{ATPase}$ can be either apical or basolateral [Quigley et al., 2011]. Together with the expression of carbonic anhydrases, $\mathrm{vH}^{+} \mathrm{ATPase}$ regulates cellular and extracellular $\mathrm{pH}$ [Quigley and Kintner, 2017]. Ionocytes also contain other transporters to regulate osmotic balance. In the mammalian lung, ionocytes are the major site of CFTR (cystic fibrosis transmembrane regulator) expression, an ion channel important for the hydration of the epithelial surface through chloride secretion [Montoro et al., 2018; Plasschaert et al., 2018]. Mucins rely on hydration and increased $\mathrm{pH}$ for unfolding and gelling [Ambort et al., 2012; Abdullah et al., 2017]. Thus, CFTR mutations cause cystic fibrosis and render the resulting mucus more dense and sticky, which interferes with its removal through ciliary beating and increases the probability for airway infections.

Club cells (formerly known as Clara cells) of the mammalian lung represent another specialized secretory cell 
type [Rokicki et al., 2016; Zuo et al., 2020]. They secrete surfactant proteins of the secretoglobin family, most prominently club cell secretory protein (CCSP, also called CC10, CC16, or uteroglobin). CCSP has anti-inflammatory properties and was implicated in modulating the behavior of migratory cells, but its complex bioactive functions are not fully understood to date [Mukherjee et al., 2007]. Furthermore, club cells contribute to detoxification by expression of xenobiotic-metabolizing P450 cytochromes (CYPs) [Rokicki et al., 2016]. They also function as facultative precursors to mucus-producing goblet cells as well as to MCCs in airway homeostasis and repair [Reynolds and Malkinson, 2010; Tata and Rajagopal, 2017]. These properties exemplify the range of functions that mucociliary secretory cells can have in mucociliary epithelia.

Pulmonary neuroendocrine cells (PNECs) of the mammalian lung as well as small secretory cells (SSCs) of the Xenopus embryonic mucociliary epidermis influence the function of the entire epithelium through modulating the behavior of another cell type. PNECs and SSCs both synthesize and secrete serotonin, although PNECs release it from their basolateral surface and SSCs secrete serotonin apically. The main function of this well-known neurotransmitter is the regulation of ciliary beating in MCCs in both systems [Lommel, 2001; König et al., 2009; Dubaissi et al., 2014; Walentek et al., 2014]. The serotonin-ciliary axis is an evolutionary ancient regulatory module frequently employed in animal hypoxia response. In the airway epithelium and the Xenopus epidermis, serotonin was shown to increase the rate of ciliary beating [Walentek et al., 2014]. A proposed mechanism for this effect is the activation of ligand-gated ion channels which could increase calcium influx that in turn speeds up ciliary motion in MCCs [Doran, 2004; Walentek et al., 2014]. In addition to serotonin secretion, SSCs produce mucins while PNECs establish neuronal connections and express an oxygen-sensing protein complex of the NADPH oxidase (NOX) family [Cutz et al., 2013; Dubaissi et al., 2014]. NOX stimulates serotonin secretion in hypoxia conditions through promoting secretory vesicle fusion with the membrane. Hence, it is attractive to hypothesize that in hypoxic conditions serotonin-producing cells release the neurotransmitter for the direct stimulation of ciliary beating to remove excess mucus and potential obstructions.

Collectively, the properties of various cell types and their interactions with each other, with non-epithelial cells, as well as with the environment determine the correct function of mucociliary epithelia. Generating, main- taining, and adapting mucociliary cell type composition and function are therefore extremely important to coordinate tissue-level behavior in development and disease.

One remarkable aspect of mucociliary epithelia is the degree of species- and organ-specific adaptations to a wide range of physiological needs and morphologies while at the same time maintaining common signalingand gene-regulatory principles. Another surprising feature of mucociliary cells is their ability to directly change fates of mature and seemingly "terminally" differentiated cells from one type to another. Such trans-differentiation behavior is relatively frequently observed in mucociliary cells, especially during developmental and pathogenic tissue remodeling.

\section{Wnt Signaling}

The Wnt signaling pathway is employed extensively during embryonic development and in adult tissue homeostasis, and its key components are conserved throughout evolution (Fig. 2a) [Steinhart and Angers, 2018]. Most commonly, signaling is induced by binding of secreted Wnt ligands to transmembrane Frizzled receptors which then activate downstream cytoplasmic Disheveled molecules. Depending on the Wnt signaling branch, for example, the canonical $\mathrm{Wnt} / \beta$-catenin pathway or the non-canonical Wnt/planar cell polarity (PCP) pathway, Wnt/Frizzled/Disheveled complexes recruit various transmembrane co-receptors and cytoplasmic mediators. Thus, Wnt signaling branches can elicit distinct cellular responses, ranging from transcriptional activation to the regulation of morphogenesis and cell polarity [MacDonald et al., 2007; Semenov et al., 2007]. As dysregulated Wnt signaling is established to contribute to a plethora of diseases, it is not surprising that it was also implicated in mucociliary dysfunction and airway disease [Lehmann et al., 2016; Baarsma and Königshoff, 2017].

Many studies have addressed the complex and reiterative functions of Wnt signaling in mucociliary epithelia in different models. Collectively, these studies suggest multiple roles for canonical Wnt pathway in regulating cell fate specification and differentiation and a role for the PCP pathway in tissue-wide and cell polarity, in particular in MCCs [Vladar and Axelrod, 2008; Wallingford, 2010; Walentek et al., 2017]. The roles of Wnt/PCP in lung development and disease were recently extensively reviewed elsewhere [Vladar and Königshoff, 2020]. Therefore, the focus here will be on canonical Wnt functions. 
Fig. 2. Wnt $/ \beta$-catenin signaling requirements in mucociliary cell types. a Simplified schematic representation of the canonical Wnt/ $\beta$-catenin pathway. Wnt ligands bind to the Frizzled receptor and recruit the LRP6 co-receptor. Intracellular mediators, for example, Disheveled, are recruited to the ligand-receptor complex, which then leads to inhibition of GSK3 $\beta$ and the stabilization of $\beta$-catenin. $\beta$-catenin can then enter the nucleus, bind to TCF/LEF transcription factors, and activate Wnt target gene expression. b Schematic representation of cell types in the mammalian trachea and their proposed requirement levels for active $W n t / \beta$-catenin signaling. Basal cells need high Wnt levels, while MCCs need elevated Wnt but at lower levels than basal cells. Goblet cells also require Wnt, but at low levels that have to be precisely controlled. c Schematic representation of cell types in the Xenopus embryonic mucociliary epidermis and their proposed requirement levels for active $\mathrm{Wnt} / \beta$-catenin signaling. Basal cells require high Wnt levels, while MCCs also show elevated Wnt activation. Ionocytes and small secretory cells do not seem to strictly rely on Wnt signaling, and the role for Wnt in goblet cells remains unresolved. See Figure 1e for key to cell types.
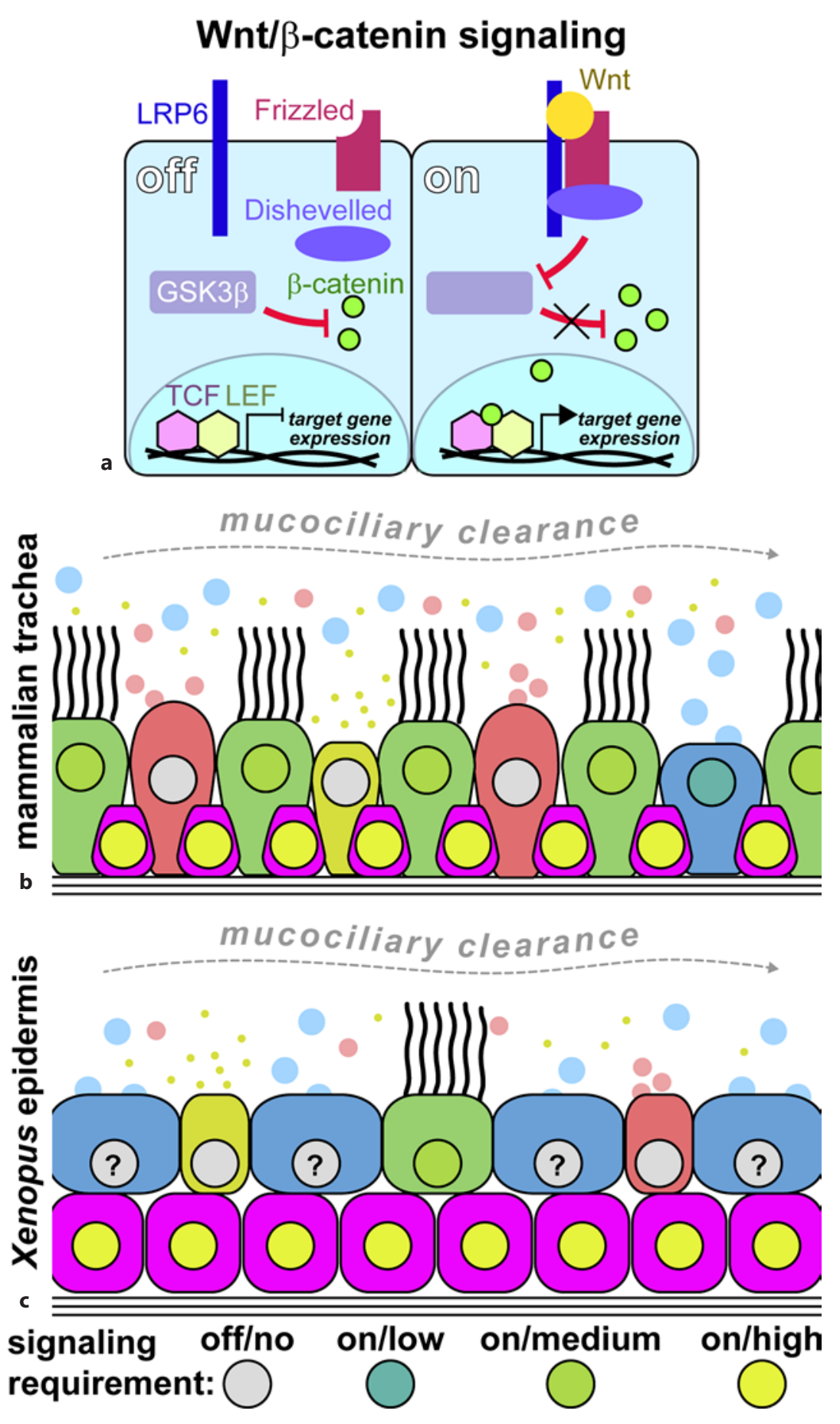

Wnt $/ \beta$-catenin was shown to control stemness and differentiation [Haas et al., 2019]. $\beta$-catenin can bind to an alternative promoter (P2) that positively regulates the expression of the $\triangle \mathrm{N}$-isoform of TP63 in humans, mice, and Xenopus [Ruptier et al., 2011; Kjolby and Harland,
2017]. $\triangle$ N-TP63 is a transcription factor required for maintaining BCs. Lack or inactivation of $\triangle N-T P 63$ expression causes excessive differentiation of epithelial cells and a loss of BCs in mucociliary epithelia [Daniely et al., 2004; Haas et al., 2019]. Interestingly, $\Delta \mathrm{N}-\mathrm{TP} 63$ is not 
strictly required for the initial establishment of mucociliary epithelia in the lung or the Xenopus epidermis. This is in line with its rather late onset of expression during mucociliary development. Nevertheless, developmental loss of $\triangle \mathrm{N}$-TP63 leads to abnormally increased numbers of MCCs [Daniely et al., 2004; Haas et al., 2019]. Tissue culture experiments further demonstrated that knockdown of $\triangle N-T P 63$ prevents establishment of an epithelium containing goblet cells, impairs proliferation, and leads to senescence [Arason et al., 2014]. These data align with the pro-proliferative role of $\mathrm{Wnt} / \beta$-catenin and $\Delta \mathrm{N}$ TP63 in other epithelial systems [Senoo et al., 2007; Arason et al., 2014; Clevers et al., 2014; Haas et al., 2019].

Overactivation of $\mathrm{Wnt} / \beta$-catenin or $\Delta \mathrm{N}$-TP63 prevents BCs from exiting the stem cell state, which then fail to undergo differentiation toward epithelial cell lineages [Mucenski et al., 2005; Reynolds et al., 2008; Schmid et al., 2017; Haas et al., 2019]. Such effects of increased Wnt/ $\beta$ catenin were reported in various models of mucociliary epithelia, and work in the Xenopus epidermis demonstrated that knockdown of $\triangle N-T P 63$ can rescue differentiation ability in the presence of high $\mathrm{Wnt} / \beta$-catenin signaling [Haas et al., 2019]. These data argue for a role of $\triangle \mathrm{N}$-TP63 as a master regulator of BC behavior and the switch between maintenance and differentiation. Furthermore, these data support the notion that the Wntinduced inhibition of epithelial differentiation is mediated to a significant degree by excessive $\triangle N$-TP63 expression in BCs.

In addition to blocking differentiation, high levels of $\mathrm{Wnt} / \beta$-catenin signaling lead to accumulation and multilayer stacking of BCs in mucociliary epithelia due to an increase in proliferation [Haas et al., 2019; Aros et al., 2020a]. Increased proliferation is also normally observed during regeneration of mammalian airway epithelia after injury, when BCs transiently express Wnt ligands [Aros et al., 2020b]. The source of canonical Wnt ligands is not limited to BCs themselves during epithelial repair as it was shown that inhibition of Wnt secretion from BCs could be compensated for by ligand secreting stromal cells of the intercartilage zone in the murine trachea [Aros et al., 2020b]. Abnormally high Wnt signaling, BC overproliferation, and decreased differentiation are also observed in premalignant lesions and in squamous lung cancer [Aros et al., 2020a]. Similarly, single-cell RNA-sequencing (scRNA-seq) of the mouse airway revealed highly proliferative and less differentiated "hillock" cell clusters [Montoro et al., 2018]. These express Krt13, a marker associated with proliferating BCs [Montoro et al., 2018; Goldfarbmuren et al., 2020]. They also express
Porcn, which encodes a protein required for Wnt secretion and is upregulated in premalignant lesions and squamous lung cancer [Montoro et al., 2018; Aros et al., 2020a]. These data suggest that "hillock" cells might be similar to cells found in early-stage premalignant lesions and thereby linking them to locally upregulated Wnt signaling.

Importantly, over-proliferation and block of epithelial cell differentiation due to $\mathrm{Wnt} / \beta$-catenin signaling can be reversed in Xenopus, human tissue culture, and in mouse airway cells. In Xenopus embryos and in differentiating air-liquid interface (ALI) cultures of immortalized human $\mathrm{BCs}$, increased $\mathrm{Wnt} / \beta$-catenin signaling through inhibition of GSK3 $\beta$ or through application of the canonical Wnt agonist R-spondin 2 (RSPO2), respectively, prevented differentiation of epithelial cells and increased numbers of BCs. Nevertheless, differentiation could be induced simply by removal of the GSK3 $\beta$ inhibitor/ RSPO2 even after long-term exposure to elevated Wnt signals and the number of BCs returned to seemingly normal levels [Haas et al., 2019]. Similarly, in chronic rhinosinusitis with nasal polyps that is associated with a failure of MCC differentiation, tissue overgrowth, and increased production of Wnt3a in the nasal epithelium, MCCs and ciliation could be rescued in vitro by application of a canonical Wnt inhibitor [Dobzanski et al., 2018]. Furthermore, recent development of a novel canonical Wnt pathway inhibitor (WIC1) that acts downstream of GSK3 $\beta$ showed that its application prevented over-proliferation, decreased $\triangle N-T P 63$ expression, and induced MCC differentiation in human and mouse in vitro $\mathrm{BC}$ cultures with overactivated Wnt signaling [Aros et al., 2020a].

Together, these findings strongly suggest that most changes in mucociliary epithelial cell type composition and morphology associated $\mathrm{Wnt} / \beta$-catenin signaling are due to abnormal behavior of BCs and loss of their ability to correctly balance maintenance, proliferation, and differentiation. Especially in diseases where loss of differentiation and an increase in BCs are observed, the use of specific inhibitors of canonical Wnt signaling offers an attractive entry point for therapeutic interventions. Understanding $\mathrm{BC}$ regulation by Wnt is also important regarding COPD and IPF, which were both associated with changes in Wnt signaling [Wang et al., 2011; Heijink et al., 2013; Baarsma and Königshoff, 2017; Shi et al., 2017] and for which limited treatment options are currently available.

In addition to the instructive role for $\mathrm{Wnt} / \beta$-catenin in BCs, data support a permissive function during the differentiation of MCCs. Multiple studies have demonstrat- 
ed that $\beta$-catenin signaling is required for motile cilia formation in MCCs [Walentek et al., 2015; Sun et al., 2018; Aros et al., 2020b]. Studies in zebrafish and Xenopus have revealed that the master regulator of motile ciliogenesis, Foxj1, is positively regulated by $\beta$-catenin and that decreased Wnt signaling affected ciliogenesis [Caron et al., 2012; Walentek et al., 2012]. Similarly, studies in the mouse and in human tissue culture indicate that Wnt signaling can have positive effects on MCCs and ciliation [Schmid et al., 2017; Aros et al., 2020a, 2020b].

Different effects on different cell types could be attributed to differential functions of Wnt ligands, for example, Wnt7a and Wnt4 in ALI-cultured human airway cells [Schmid et al., 2017]. On the other hand, analysis of canonical Wnt-signaling reporter activity in the Xenopus embryonic epidermis as well as in the developing mouse airway indicated that Wnt signaling levels differ between BCs and differentiating MCCs, with MCCs showing lower signaling levels than BCs. Thus, intermediate Wnt signaling levels are compatible with successful MCC differentiation from BCs, while at the same time supporting the robust expression of $f o x j 1$ as one of multiple transcription factors employed in the coordinated control of the multiciliogenesis program [Walentek and Quigley, 2017]. Differential Wnt signaling levels between BCs and MCCs could be generated through cell type specific receptor expression levels, as differentiating cells drastically change their transcriptional program, a hypothesis also supported by scRNA-seq data [Ruiz García et al., 2019]. Furthermore, apical-basal asymmetric cell division together with asymmetric distribution of the canonical Wnt co-receptor LRP6 were shown to prime basally located cells for high Wnt signaling activation during Xenopus mucociliary epidermal development preceding $\triangle N$-TP63 expression [Clevers et al., 2014; Huang and Niehrs, 2014]. Either way, BCs are likely sensitized to percept canonical Wnt signaling and can react to the same amount of Wnt ligands by stronger downstream signaling activation than differentiated epithelial cells, including MCCs.

In contrast to BCs and MCCs, the precise functions of $\mathrm{Wnt} / \beta$-catenin in goblet, club, and other secretory cells are less clear. In club cells, canonical Wnt signaling is dispensable for specification, differentiation, and maintenance [Zemke et al., 2009]. In fact, an increase in canonical Wnt signaling disfavors proximal airway and club cell fate during regeneration and organoid preparation [Frank et al., 2016]. Instead, there is a connection between Wnt/ $\beta$-catenin and the specification of goblet cells as well as with development of a mucus hyperplastic phenotype in the mammalian lung. The main sites of mucin-secretory cell specification in the healthy mouse and human lungs are the submucosal glands where these cells are called mucous cells (in contrast to epithelial goblet cells) (Fig. 1b) [Hogan et al., 2014]. Those glands are formed in the trachea and bronchi in humans, and their ducts terminate between cartilage rings. Full development of mouse submucosal glands depends on Wnt3a, canonical Wnt signaling, and the transcription factor Lef-1, which in turn mediates $\beta$-catenin-dependent transcription [Driskell et al., 2004, 2007; Xie et al., 2014]. While this is an indirect effect of Wnt on mucous cells, it should be noted that loss of developmental Wnt signaling could in principle lead to a deficiency in mucus production.

Dysfunction of the Wnt/Frizzled co-receptor Ryk in the mouse airway epithelium was shown to decrease airway epithelial canonical Wnt activity and to lead to goblet cell hyperplasia [Kim et al., 2019]. The remodeling of the epithelium in this condition was associated with a strong increase in Mucin5A/C and 5B, in line with an overabundance of mature goblet cells. Deletion of $R y k$ also caused a change in Wnt ligand expression, that is, expression levels of Wnt2, Wnt7b, and of the canonical Wnt agonist Rspo2 were all decreased, providing an explanation for the overall decreased $\mathrm{Wnt} / \beta$-catenin activity (but not a full loss of signaling) [Kim et al., 2019]. The increase in goblet cell numbers was inversely correlated to the number of club cells. Together, these data suggest that appropriate Wnt signaling suppresses the overproduction of goblet cells, thereby promoting maintenance of club cells. This is in line with another report from the mouse airway that revealed an enrichment of goblet cell marker expression in low Wnt-positive cells over Wnt-negative or high Wnt-positive cells, while such enrichment was not found for club cell markers, and MCC markers were enriched in high Wnt-positive cells [Hu et al., 2020]. Furthermore, an increase in canonical Wnt signaling during ALI differentiation of immortalized human BCs was found to increase $M u c i n 5 B$ expression, while the expression of the club cell marker SCGB1A1 was strongly decreased [Haas et al., 2019]. On the other hand, treatment of such cultures with the canonical Wnt antagonist DKK1 did not change Mucin5B or SCGB1A1 expression and did not result in a loss of either secretory cell type.

Although these data are not definitively conclusive regarding the roles of Wnt in secretory cells of mucociliary epithelia, they do support the idea that correctly regulated Wnt signaling is also required (directly or possibly indirectly) to control proper secretion in mucociliary epithelia and that gain and loss of Wnt can lead to overabundance of goblet cells or to an increase in mucus produc- 
tion. This is in agreement with studies on patient-derived material where COPD tissue was associated with goblet cell hyperplasia and reduced Wnt signaling [Wang et al., 2011].

In summary, a model emerges that implies an instructive and dominant role for canonical Wnt signaling in BC maintenance, proliferation, and the inhibition of differentiation, while supporting a permissive function for strictly balanced and lower Wnt levels during differentiation and maintenance of MCCs and secretory cells (Fig. 2b, c). Nevertheless, additional studies further clarifying the roles of Wnt signaling in secretory cells and the regulation of mucin secretion are urgently needed.

\section{Notch Signaling}

Notch signaling is another highly evolutionary conserved cell signaling pathway, but in contrast to Wnt, Notch is strictly dependent on cell-cell contacts (Fig. 3a) [Henrique and Schweisguth, 2019]. Both Notch receptors and ligands are transmembrane proteins and require processing during signaling activation. Upon Delta-like (Dll) or Jagged (Jag) ligand binding to Notch receptors, the activated extracellular portion of the complex is cleaved off from the receiving cell by metalloproteases. Next, $\gamma$-secretase cleaves off the cytoplasmic portion of the receptor to release the Notch intracellular domain (NICD). This allows NICD to translocate to the nucleus where it interacts with CSL/RBPJ transcription factors. In the absence of NICD, CSL/RBPJ bind co-repressor molecules that can directly suppress transcription of target genes. Additionally, the repressive CSL/RBPJ complex also recruits chromatin modifying proteins, which cause long-term epigenetic silencing of the genomic region [Lake et al., 2014; Giaimo et al., 2017]. When NICD binds to CSL/RBPJ, it displaces bound co-repressors and facilitates recruitment of co-activators (e.g., Mastermind and p300) for target gene transcription [Henrique and Schweisguth, 2019]. As Notch signaling does not act through an amplifying second messenger cascade, the amount of receptor activation directly scales with the resulting level of signaling activity.

The crucial role for Notch signaling in mucociliary epithelia has been the subject of extensive studies over the past 20 years [Deblandre et al., 1999]. These studies have revealed that Notch is the main signaling pathway directing cell fate decisions in mucociliary epithelial development, maintenance, and disease. While seemingly simple in its signaling mechanism and being probably the most extensively studied signaling pathway in mucociliary ep-

Mucociliary Signaling ithelia, not all details of Notch signaling function are fully understood to date.

Notch signaling in the mammalian airway as well as in the Xenopus embryonic epidermis was shown to play a major role in the specification of MCCs and secretory cells (Fig. 3b, c) [Stubbs et al., 2006; Tsao et al., 2009; Rock et al., 2011]. In the Xenopus epidermis mucociliary epithelium, low Notch signaling favors specification of ionocytes and MCCs. Consequently, inhibition of NICD transcriptional activity by a dominant-negative DNA-binding mutant of the CSF/RBPJ homolog SuH (SuH-DBM) or a dominantnegative form of Mastermind leads to excessive production of ionocytes and MCCs, while overexpression of a constitutive active NICD suppresses ionocyte and MCC specification [Deblandre et al., 1999; Stubbs et al., 2006; Quigley et al., 2011; Walentek, 2018]. It was further shown that overexpression of intermediate NICD levels in Xenopus increases the number of SSCs, that is, a secretory cell type that also produces mucins [Walentek, 2018; Kurrle et al., 2020]. Similarly, data from the mouse airway demonstrated that low Notch levels lead to specification of MCCs, while high Notch levels promote the production of club secretory cells [Guseh et al., 2009; Tsao et al., 2009]. Accordingly, NICD overexpression in ALI-cultured human BCs also caused an overproduction of club cells and increased expression of SGB1A1 and Mucin5A/C, while simultaneously decreasing the number of MCCs and the expression of ciliated cell markers [Gomi et al., 2015]. The regulation of the mucusproduction master transcription factor Spdef was also shown to be positively Notch regulated [Chen et al., 2009, 2018; Guseh et al., 2009]. Furthermore, excessive Notch signaling in the mouse airway causes mucous cell metaplasia [Guseh et al., 2009].

Nevertheless, it is not always clear if Notch-induced mucin overexpression is due to overspecification of goblet cells or if mucin production is transiently upregulated in club cells, a phenomenon observed upon airway infection and inflammation [Evans et al., 2004; Méndez et al., 2019; $\mathrm{He}$ et al., 2020]. Arguments in favor of Notch-induced overproduction of goblet cells as cause for mucous cell metaplasia are derived from studies that have shown a requirement for Notch signaling in IL-13 cytokine mediated goblet cell hyperplasia models as well as from studies demonstrating that Spdef is required for both goblet cell specification and Mucin5A/C and 5B production [Chen et al., 2009, 2018; Danahay et al., 2015]. Goblet cell fate can be induced by addition of IL-13, but this effect can be blocked by inhibition of Notch signaling [Tyner et al., 2006; Guseh et al., 2009; Danahay et al., 2015]. IL-13 is upregulated in chronic lung disease, in mouse models for airway inflam- 
Fig. 3. Notch signaling requirements in mucociliary cell types. a Simplified schematic representation of the Notch pathway. Transmembrane Notch ligands from the Delta or Jagged families bind to transmembrane Notch receptors. Upon activation, matrix metalloproteases (MMPs) cleave the extracellular portion of the complex and $\gamma$-secretase cleaves off the Notch intracellular domain (NICD). NICD can then enter the nucleus, displace repressors from the RBPJ DNA-binding complex, and recruit transcriptional co-activators to initiate gene transcription. b Schematic representation of cell types in the mammalian trachea and their proposed requirement levels for active Notch signaling. Goblet, club cells, and ionocytes show elevated Notch signaling, although at different levels, while MCCs and basal cells were proposed to be Notch independent. c Schematic representation of cell types in the Xenopus embryonic mucociliary epidermis and their proposed requirement levels for active Notch signaling. Basal and goblet cells show high Notch levels, and small secretory cells also require higher Notch levels for specification. Ionocytes and MCCs require low/no Notch signaling for specification and maintenance. See Figure 1e for key to cell types.

\section{Notch signaling}
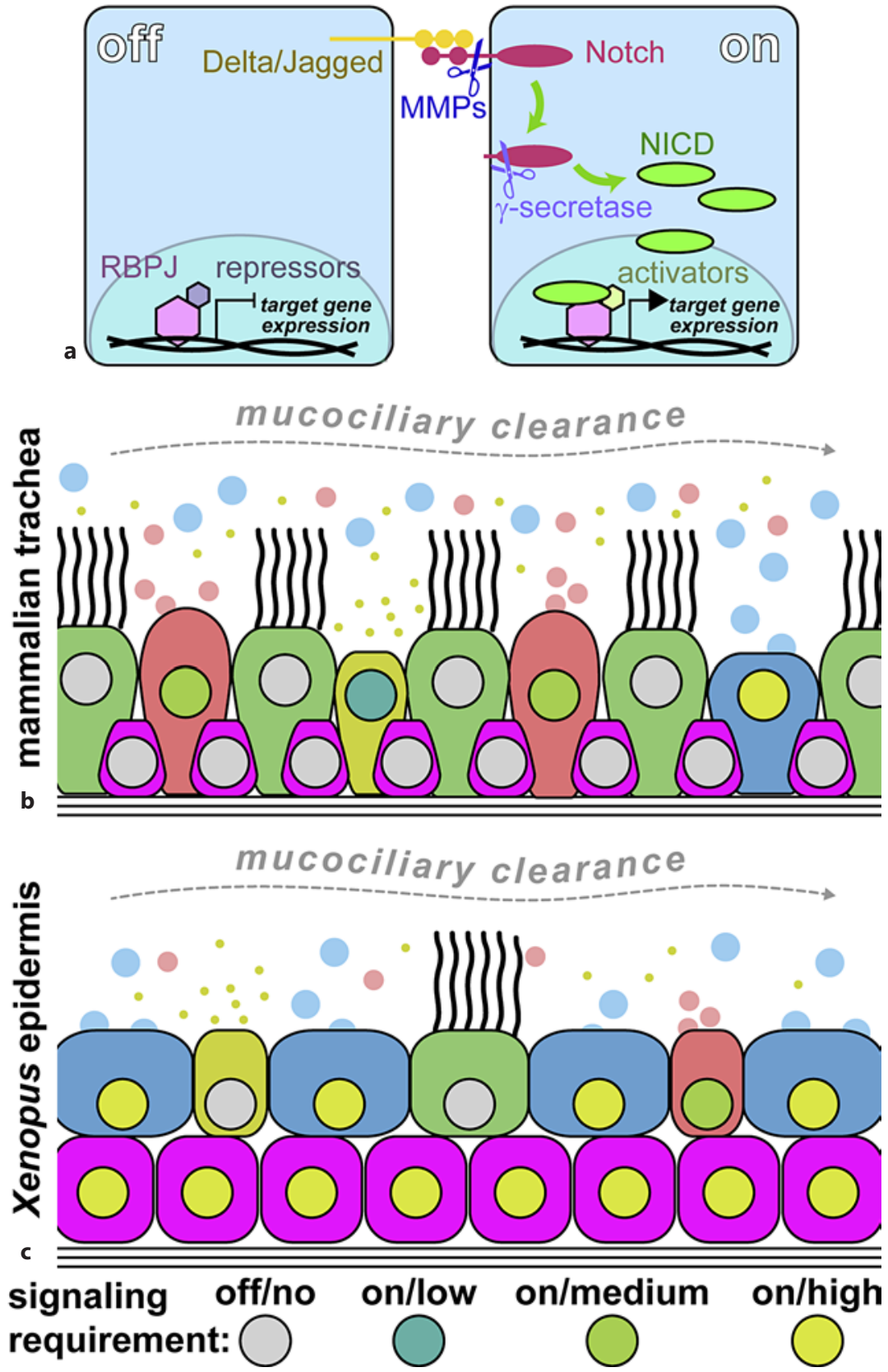

mation, and is also known to cause an increase in goblet cells in human airway epithelial cell cultures that are usually not producing many goblet cells [Walters et al., 2013]. IL-13 acts through the transcription factor STAT6, which regulates Spdef in a positive fashion and suppresses Foxj1 expression [Gomperts et al., 2007; Yu et al., 2011]. Spdef in turn activates $M u c i n 5 A / C$ and $5 B$ expression [Parker et al., 2013]. Therefore, synergistic effects between IL-13/ STAT6 and Notch signaling are likely as both pathways regulate Spdef and can lead to mucous cell metaplasia. In light of these data it seems confusing that expression of Notch ligands and receptors in COPD tissue was found to 
be decreased, although COPD is highly correlated with mucous cell metaplasia [Tilley et al., 2009]. A possible explanation could be that over the course of the disease, chronic inflammation becomes so strong that it can drive $S P D E F$ and $M U C I N 5 A / C, 5 B$ expression even when Notch signaling is attenuated. Thus, further studies are urgently needed to gain more mechanistic insights into the connections between Notch signaling, goblet/mucous cells, and chronic airway diseases.

More data are also needed regarding the Notch regulation of ionocytes in the mammalian lung as in contrast to the Xenopus epidermis, where this cell type was initially described, Notch inhibition was shown to negatively affect ionocyte abundance [Quigley et al., 2011; Plasschaert et al., 2018]. Conversely, SSCs that share the characteristic serotonin production and secretion with mammalian PNECs are dependent on high Notch signaling in the frog, and the opposite is true for mouse PNECs, which are increased in numbers upon developmental deletion of multiple Notch receptors in the epithelium [Morimoto et al., 2012; Walentek, 2018; Kurrle et al., 2020]. In Xenopus, Notch inhibition was also shown to lead to downregulated expression of $\triangle N-T P 63$, while in the mammalian airways, Notch seems largely dispensable for BCs, and elevated Notch is required for differentiation of luminal epithelial cell types [Rock et al., 2011; Sirour et al., 2011].

All these differences could well be due to species-specific aspects or potentially be related to the fact that the airway epithelium is derived from the endoderm, while the epidermal mucociliary epithelium in Xenopus is derived from the ectoderm. Additional discrepancies in studies could arise from different starting points for epithelial development in vivo and in vitro. In the airways and in the Xenopus epidermis, $\triangle \mathrm{N}$-TP63-positive BCs are initially not abundant during early phases of development, while in ALI culture, preparations derived from mature BC-containing airway epithelia are used, and BCs most likely represent the starting point for differentiation of all epithelial cells. All the above issues require further studies as it seems counterintuitive to assume such fundamental differences between systems, while otherwise the principles of Notch-mediated cell fate specification are so highly conserved (Fig. 3b, c).

\section{BMP Signaling}

BMP signaling belongs to the TGF $\beta$ superfamily of morphogenetic signaling pathways that regulate multiple aspects of cell and tissue behavior in development and disease (Fig. 4a) [Dutko and Mullins, 2011]. Activation of BMP signaling is triggered by binding of BMP homo- or heterodimers to a combination of transmembrane type I and type II serine-threonine kinase receptors. Upon ligand binding, complexes are formed which facilitate intermolecular auto-phosphorylation of the intracellular receptor domains. Type I receptors subsequently activate cytoplasmic Smad proteins through phosphorylation of Smad1/5/8, which allows heterodimerization with Smad4, nuclear translocation, DNA binding, and transcriptional regulation of BMP target genes.

While BMP signaling was shown to definitively influence mucociliary epithelia, less is known about the precise functions of BMP signaling as compared to Wnt and Notch signaling.

In the developing Xenopus epidermis as well as in ALI cultures of human airway cells, BMP overactivation was shown to suppress differentiation of mature MCCs and secretory cells [Cibois et al., 2015]. On the other hand, knockdown of BMPs in Xenopus increased the production of MCCs, ionocytes, and SSCs, while it decreased the number of BCs [Cibois et al., 2015]. Similarly, BMP signaling inhibition by application of the antagonist Noggin promoted differentiation of MCCs and Mucin5A/C-positive secretory cells in normal ALI-cultured human airway cells as well as in cell cultures using cystic fibrosis patient cells [Cibois et al., 2015]. These studies have also identified a positive role for BMP in the intercalation of progenitor cells into the epithelial lining. These data suggest that BMP signaling could have a dual role in the regulation of $\mathrm{BC}$ differentiation into mature cells as well as in regulating successful morphogenesis of the epithelium following cell fate specification (Fig. 4b).

Inhibition of Smad-mediated signaling was further shown to allow for BC expansion in vitro, and studies of mouse tracheospheres demonstrated that BMP inhibitors promote proliferation without affecting epithelial cell fate decisions, while exogenous Bmp4 application inhibited proliferation and differentiation [Mou et al., 2016; Tadokoro et al., 2016; Zuo et al., 2019]. Furthermore, BMP activity is transiently increased during airway epithelial repair in the mouse but decreased during differentiation and regeneration of the epithelium [Tadokoro et al., 2016]. Analysis of Smads in the mouse airway also showed nuclear Smad protein localization in differentiated airway cells but not in BCs, which is in line with the ability of BCs to proliferate [Mou et al., 2016; Tadokoro et al., 2016]. The temporal use of BMP proteins and subsequent application of BMP antagonists during differentiation was also described in protocols for the generation of air- 
way epithelial cells from iPSCs, which further supports a dual role of BMP in proliferation and differentiation [Huang et al., 2014, 2015].

In mouse lung development, BMP signaling reporter analysis revealed an absence of signaling activity during early epithelial development but an onset of reporter signal in the epithelium during stages of mucociliary differentiation [Sountoulidis et al., 2012]. In the adult lung epithelium, BMP activity was attenuated and only found in few epithelial cells, possibly labeling newly differentiated cells during homeostatic epithelial cell replacement [Sountoulidis et al., 2012]. In agreement with the finding that BMP signaling does not affect cell fate decisions of different epithelial cell types, BMP reporter activity was found in club cell, MCCs, and PNECs [Sountoulidis et al., 2012].

BMP signaling was also implicated as a positive regulator of epithelial to mesenchymal transition (EMT) during regeneration of airway epithelial lesions, in which cells at the edges of the injury site migrate to cover the affected area [Molloy et al., 2008; McCormack et al., 2013]. A positive effect of BMP in cell migration could also represent a parallel to the described requirement for BMP during cell intercalation in Xenopus epidermal mucociliary development where cells have to relocate from the deep into the epithelial layer (Fig. 4b) [Cibois et al., 2015].

Together, data on BMP signaling in mucociliary development and repair indicate a need for dynamic, precise, and context-specific regulation of BMP signaling levels in $\mathrm{BC}$ proliferation and specification as well as in epithelial cell differentiation and migration. While further studies into the roles of BMP signaling in chronic airway diseases are necessary, reports on the elevated state of BMP signaling during cigarette smoke-induced remodeling of the airway epithelium, associated with COPD, fit the proposed roles for BMP derived from animal models [Zuo et al., 2019]. Therefore, additional data on BMP functions in human airway disease could provide important new insights for the benefit of developing treatment options for COPD patients.

\section{Other Signaling Pathways in Mucociliary Epithelia}

Additional signaling pathways likely affect mucociliary and airway functions, although perhaps by modulating cellular responses to the key signaling pathways or by modifying Notch, Wnt, and BMP signaling at the ligand, receptor, or co-regulator expression levels. Unfortunately, less data are available on the functions of other path-

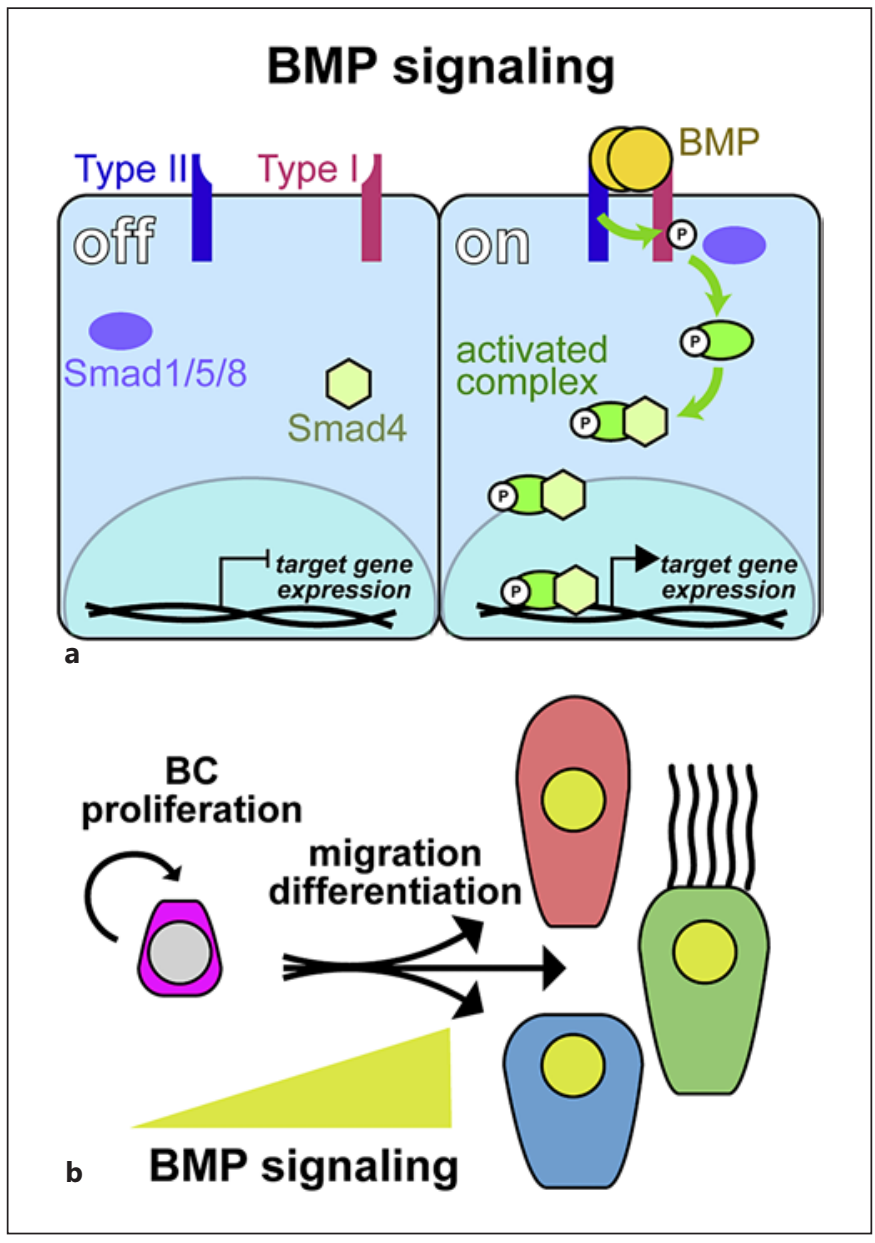

Fig. 4. BMP signaling requirements in mucociliary cell types. a Simplified schematic representation of the BMP pathway. BMP ligand dimers bind Type I/Type II transmembrane receptors. Activated Type II receptor cross-autophosphorylates Type I intracellularly, which, in turn, activates Smad proteins by phosphorylation. Activated Smad1/5/8 then binds Smad4, and the complex can enter the nucleus, bind to DNA, and activate target gene expression. b Schematic representation of proposed BMP-regulated events in vertebrate mucociliary epithelia. Yellow triangle indicates increasing BMP levels in migration and differentiated cells. Low/no BMP signaling is required in basal cells for maintenance and proliferation, while elevated BMP signaling levels are observed during migration and insertion of cell types into the epithelial cell layer during differentiation. See Figure 1e for key to cell types.

ways in mucociliary research models and in human disease. FGF and Hedgehog signaling were implicated in mucociliary epithelial BC regulation, in the differentiation of epithelial cell types during regeneration, and in COPD and IPF [Peng et al., 2015; Yuan et al., 2018; Danopoulos et al., 2019; Hou et al., 2019; Wang et al., 2020]. In part, the observed effects could be traced back to sub- 
sequent changes in Wnt or Stat6 signaling, which are known to affect BCs, differentiation, and mucus production more directly [Peng et al., 2015; Yuan et al., 2018; Danopoulos et al., 2019; Hou et al., 2019; Wang et al., 2020]. A recent study also implicated Hedgehog signaling in COPD and possibly more directly in MCC ciliation [Belgacemi et al., 2020]. Clearly, more research is needed to uncover the precise functions of other signaling pathways to promote our understanding of developmental, regenerative, and disease mechanisms. Understanding the modulatory effects of other pathways on airway epi- thelia, even if those turn out to be indirect, could still provide attractive entry points for drug development, diagnosis, and ultimately for novel therapies.

\section{Trans-Differentiation in Mucociliary Homeostasis and Tissue Remodeling}

In the traditional view, a precursor or stem cell gives rise to a differentiated cell that does not change identity after completing differentiation. This is the general text-
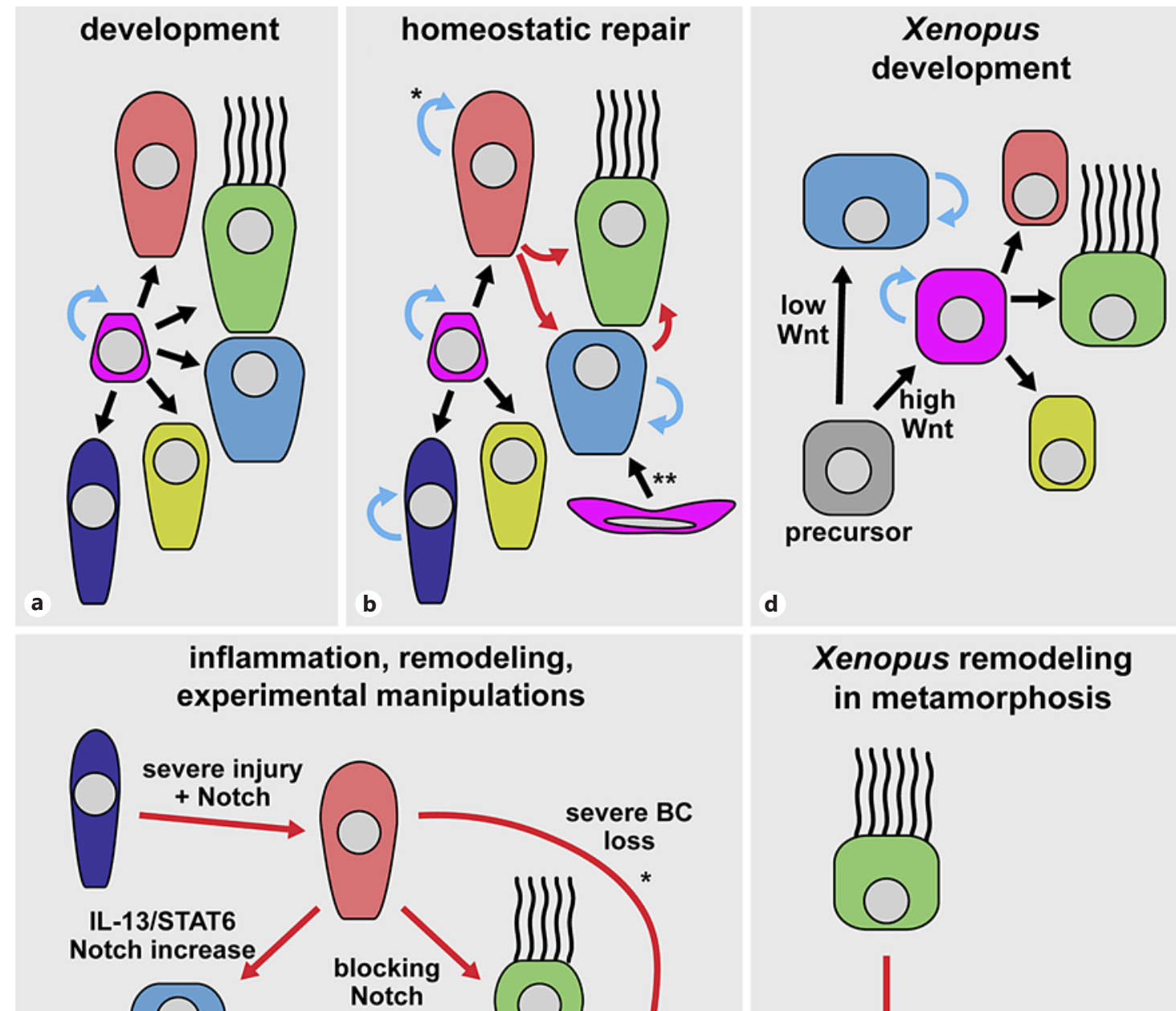

IL-13/STAT6 Notch increase
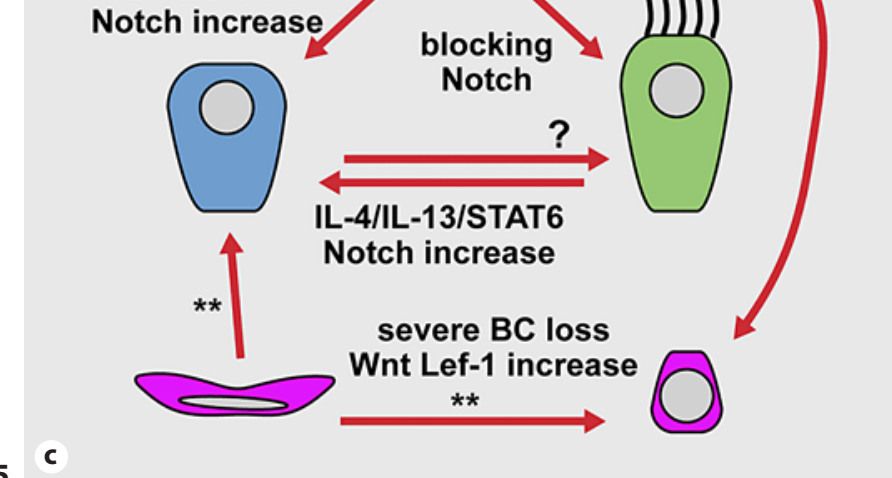
5 c

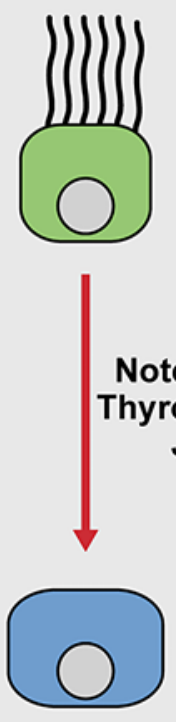


book concept of "terminal differentiation". This view has been challenged over the years, perhaps first when John Gurdon was able to show that the transplantation of adult skin cell nuclei into denucleated oocytes led to reprogramming and that the recombined egg could give rise to a fully developed frog [Gurdon, 1962]. This finding was later followed up in mammalian cells where the use of Yamanaka's transcription factor cocktail could reprogram cells into induced pluripotent stem cells (iPSCs) [Takahashi and Yamanaka, 2006]. Since then, more and more cases of naturally or disease-induced fate changes in fully differentiated cells were reported as well [Merrell and Stanger, 2016; Wells and Watt, 2018]. The direct cell fate change from one differentiated cell type into another is referred to as trans-differentiation. In most tissues trans-differentiation is not very common, but in airway mucociliary epithelia, trans-differentiation events are rather frequent (Fig. 5) [Rock et al., 2010; Tata and Rajagopal, 2017]. To highlight some aspects of mucociliary trans-differentiation processes, relevant findings from developmental and disease models are briefly summarized here, especially because they closely relate to signaling regulation of mucociliary epithelia.

During normal Xenopus epidermal and mammalian airway epithelial development, all cell types are thought to develop from epithelial precursors and BCs (Fig. 5a, d) [Bilodeau et al., 2014; Hogan et al., 2014; Walentek and Quigley, 2017; Collins et al., 2020; Dubaissi, 2020]. This seems to hold true in cases where large epithelial lesions occur in the airway epithelium [Pardo-Saganta et al., 2015a; Aros et al., 2020b]. Furthermore, studies suggest that ionocytes and PNECs are derived directly from BCs in adult lung homeostasis (Fig. 5b) [Tata and Rajagopal, 2017]. Hence, it was surprising when club cells were

Fig. 5. Mucociliary cell lineages and signaling in development, homeostasis, and remodeling. a-e Simplified schematic representation of mucociliary cell types and their specification or trans-differentiation during normal development and homeostasis as well as in experimental models of inflammation, remodeling, and severe injury. See Figure 1e for key to cell types. a In mammalian airway development, basal cells can self-renew and generate all epithelial cell types. b In mammalian airway homeostasis and repair, basal cells, club cells, PNECs, and goblet cells can self-renew. Additionally, MCCs and goblet cell populations can be maintained by trans-differentiation from club cells. In the submucosal glands, mucous cells are generated from myoepithelial cells. c Trans-differentiation events in mammalian airway inflammation, tissue remodeling (e.g., in chronic airway disease), and after experimental manipulation. Club cells can trans-differentiate into MCCs and goblet cells and can de-differentiate into basal cells upon severe found to be facultative precursor cells for the majority of MCCs during mammalian airway homeostasis and repair (Fig. 5b) [Hogan et al., 2014]. In fact, club cells were proposed to be the stem cells of mucociliary airway epithelia, and only relatively recent studies have definitely identified multiple populations of adult stem cells along the proximal-distal axis of the mammalian lung [Rock et al., 2009; Reynolds and Malkinson, 2010; Zuo et al., 2015].

In the mouse bronchioles, club cells give rise to MCCs and maintain the club cell population through self-renewal [Rawlins et al., 2009]. In the trachea, club cells also give rise to MCCs in homeostatic conditions as well as after injury, but they rarely self-renew [Rawlins et al., 2009]. Hence, club cells in the trachea are likely predominantly specified from BCs in homeostatic conditions, but MCCs are replenished from epithelial club cells. Specification of MCCs from club cells is regulated by Notch signaling (Fig. 5c). Notch reduction by inhibitory antibodies has shown that blocking Jag1/Jag2 leads to massive transdifferentiation of club cells into MCCs [Lafkas et al., 2015]. When this treatment was terminated, club cells slowly reappeared in the epithelium. This phenomenon could be related to the specific decoration of the different mucociliary cell types by different Notch ligands, that is, Jag1 and Jag2 were shown to be enriched in MCCs [Lafkas et al., 2015]. On the other hand, Notch 1 and 2 receptor blocking could elicit the same effect on mucociliary composition, and Notch 1 and 2 were shown to be enriched in club cells [Lafkas et al., 2015]. Further studies revealed that secretory cells, MCCs, and BCs each show specific enrichment of Notch ligands and receptors [Pardo-Saganta et al., 2015b]. Thus, it is attractive to speculate that this allows the mucociliary system to maintain correct cell type composition during homeostasis by providing

basal cell loss. After severe injury, PNECs can also trans-differentiate into club cells. Trans-differentiation between MCC and goblet cell fates were reported in both directions. Myoepithelial cells in the submucosal glands can generate mucous cells but also transdifferentiate into epithelial basal cells after severe basal cell loss. d Mucociliary development in the Xenopus embryonic mucociliary epidermis. All epithelial cell types are derived from precursor cells that mature into basal cells. Basal cells and goblet cells can both divide and self-renew. e Multiciliated to goblet cell trans-differentiation at the onset of Xenopus metamorphosis was demonstrated in the Xenopus epidermis and is triggered by increased Notch signaling and modulated by thyroid hormone and Jak/Stat signaling. Black arrows show cell type transitions from stem/precursor cells, blue arrows show proliferation/self-renewal, and red arrows show trans- and de-differentiation events. *, in the bronchiole only; ${ }^{* *}$, in the submucosal glands only. 
Notch-mediated information to the surrounding epithelial cells and BCs.

Upon airway infection or allergen sensitization, club cells can also express Spdef, start mucin production, and change their morphology toward goblet cells [Evans et al., 2004; Chen et al., 2009]. Furthermore, these changes are reversible. Like in the trans-differentiation from club to ciliated cell, club to goblet cell change is Notch dependent and can be inhibited by blocking Notch signaling (Fig. 5c) [Lafkas et al., 2015]. Infection and allergen sensitization were shown to induce cytokine secretion, and the IL-4/IL-13/STAT6 pathway promotes Spdef expression together with Notch.

Similar to club cells, inflammation and IL-4/IL-13/ STAT6 pathway activation can induce cellular changes and mucus production in MCCs through STAT6 (Fig. 5c) [Tyner et al., 2006]. Furthermore, MCCs were reported to lose cilia through STAT6-mediated repression of Foxj1 during trans-differentiation [Gomperts et al., 2007]. These effects were co-dependent on the anti-apoptotic effect of EGF signaling in MCCs [Tyner et al., 2006]. Changes induced by IL-13 could be blocked by inhibition of Notch signaling, further supporting the dominant role of Notch in cell fate specification and maintenance [Guseh et al., 2009; Danahay et al., 2015; Lafkas et al., 2015]. MCC to goblet cell trans-differentiation is highly controversially debated in the airway field, in part because it is hard to imagine that such an extremely differentiated cell type could change fate and remodel its highly specialized morphology. Furthermore, lineage tracing experiments in mice failed to confirm maintenance of goblet cells that were derived from MCCs, and it was observed that goblet cells can trans-differentiate into MCCs as well [Turner et al., 2011; Pardo-Saganta et al., 2013; Ruiz García et al., 2019].

In the Xenopus epidermis, MCCs are lost at the onset of metamorphosis, and MCC to goblet cell trans-differentiation was proposed in this system as well as based on costaining of cells for both cilia and mucus markers [Nishikawa et al., 1992]. A recent study has provided additional evidence for MCC trans-differentiation in Xenopus, where it was demonstrated that during trans-differentiation, MCCs downregulate foxj1 gene expression, begin mucin production as well as cilia retraction, and where loss of basal body proteins was observed in the course of the process [Tasca et al., 2021]. In contrast to the inflammatory response of MCCs in the mammalian airways, this process in Xenopus was induced by an upregulation of Notch ligand expression in the mesoderm underlying the mucociliary epidermis, and cell fate change could be blocked by inhibition of Notch in this system as well [Tasca et al., 2021]. Jak/Stat signaling also had a similar anti- apoptotic effect as in mammals (Fig. 5c, e) [Tasca et al., 2021]. Furthermore, overexpression of NICD specifically in cells committed to MCC cell fate could induce identity change to goblet cells during initial development of the epidermis [Tasca et al., 2021]. Thus, these data support the possibility of MCC trans-differentiation into goblet cells in the mammalian airway and suggest that the basis for such changes in disease could be the reactivation of an evolutionarily conserved mechanism normally employed during developmental tissue remodeling.

Equally remarkable as trans-differentiation of MCCs into goblet cells is the ability of club cells to trans-differentiate into BCs under conditions where a majority of endogenous BCs were lost (Fig. 5c) [Tata et al., 2013]. Ablation of more than $80 \%$ of $\mathrm{BCs}$ lead to in vivo dedifferentiation of club cells into BCs that could function like normal stem cells and self-renew over an extended period of time. Similarly, BCs derived from club cells were observed in organoid-formation assays in vitro [Tata et al., 2013]. Upon severe injury, myoepithelial cells lining the submucosal glands were further shown to function as stem cells for submucosal mucous cells and to migrate to the airway surface mucociliary epithelium to trans-differentiate into BCs, which then gave rise to MCCs, club cells, and goblet cells (Fig. 5c) [Lynch et al., 2018]. This change depended on the activation of canonical Wnt signaling and Lef- 1 activation, and overexpression of Lef- 1 in myoepithelial cells was sufficient to induce fate change into $\mathrm{BCs}$.

In summary, data from mammalian and Xenopus mucociliary epithelia have demonstrated a remarkable flexibility of cell fates and frequent trans-differentiation events during normal homeostasis, developmental tissue remodeling, airway epithelial repair upon injury, and in chronic airway diseases. In most cases, these cell fate changes could be linked to a changing signaling environment, especially in Wnt and Notch signaling, as well as to inflammation and cytokine response that likely cooperate with or alter these 2 pathways.

\section{Conclusion}

Extensive work has revealed many links between Wnt, Notch, BMP, and other signaling pathways to normal development as well as to pathogenesis of mucociliary epithelia, most prominently in the airways. Further understanding of signaling functions in regeneration and tissue remodeling in association with chronic lung disease will be instrumental for the future development of better treatment options for patients. Hence, additional studies 
are necessary to shed more light on these signaling mechanisms under normal conditions and during disease. As airway infections and chronic lung diseases are among the most common causes of death worldwide, increasing our mechanistic understanding of the signaling control of mucociliary epithelia should remain a priority in basic biological and airway pathogenesis research.

\section{Acknowledgement}

P.W. thanks all the members of the Walentek lab for discussions, ideas, and critical comments. P.W. also thanks the Xenopus and mucociliary research communities for their contributions to the field as well as for communication of unpublished data, sharing of resources, and fruitful discussions on the topic of mucociliary epithelia and airway diseases mechanisms.

\section{Conflict of Interest Statement}

The author has no conflicts of interest to declare.

\section{Funding Sources}

P.W. and work in the Walentek lab was supported by the NHLBI (K99HL127275) and the Deutsche Forschungsgemeinschaft (DFG) under the Emmy Noether Program (grant WA3365/2-1) and under Germany's Excellence Strategy (CIBSS - EXC-2189 Project ID 390939984).

\section{Author Contributions}

P.W. reviewed the literature and wrote the manuscript.

\section{References}

Abdullah LH, Evans JR, Wang TT, Ford AA, Makhov AM, Nguyen K, et al. Defective postsecretory maturation of MUC5B mucin in cystic fibrosis airways. JCI Insight. 2017;2: e89752.

Alyass A, Turcotte M, Meyre D. From big data analysis to personalized medicine for all: Challenges and opportunities. BMC Med Genomics. 2015;8:33-12.

Ambort D, Johansson ME, Gustafsson JK, Nilsson HE, Ermund A, Johansson BR, et al. Calcium and $\mathrm{pH}$-dependent packing and release of the gel-forming MUC2 mucin. Proc Natl Acad Sci USA. 2012;109(15):5645-50.

Arason AJ, Jonsdottir HR, Halldorsson S, Benediktsdottir BE, Bergthorsson JT, Ingthorsson S, et al. DeltaNp63 has a role in maintaining epithelial integrity in airway epithelium. PLoS One. 2014;9(2):e88683.

Aros CJ, Paul MK, Pantoja CJ, Bisht B, Meneses LK, Vijayaraj P, et al. High-throughput drug screening identifies a potent Wnt inhibitor that promotes airway basal stem cell homeostasis. Cell Rep. 2020a;30(7):2055-e5.

Aros CJ, Vijayaraj P, Pantoja CJ, Bisht B, Meneses LK, Sandlin JM, et al. Distinct spatiotemporally dynamic Wnt-secreting niches regulate proximal airway regeneration and aging. Cell Stem Cell. 2020b;27(3):413-e4.

Baarsma HA, Königshoff M. "WNT-er is coming": WNT signalling in chronic lung diseases. Thorax. 2017;72(8):746-59.

Ballweg K, Mutze K, Königshoff M, Eickelberg O, Meiners S. Cigarette smoke extract affects mitochondrial function in alveolar epithelial cells. Am J Physiol Lung Cell Mol Physiol. 2014;307(11):L895-907.
Belgacemi R, Luczka E, Ancel J, Diabasana Z, Perotin JM, Germain A, et al. Airway epithelial cell differentiation relies on deficient Hedgehog signalling in COPD. EBioMedicine. 2020; 51:102572.

Bilodeau M, Shojaie S, Ackerley C, Post M, Rossant J. Identification of a proximal progenitor population from murine fetal lungs with clonogenic and multilineage differentiation potential. Stem Cell Reports. 2014;3(4):634-49.

Brooks ER, Wallingford JB. Multiciliated cells. Curr Biol. 2014;24(19):R973-82.

Caron $\mathrm{A}, \mathrm{Xu} \mathrm{X}$, Lin X. Wnt $/ \beta$-catenin signaling directly regulates Foxj1 expression and ciliogenesis in zebrafish Kupffer's vesicle. Development. 2012;139(3):514-24.

Chen G, Korfhagen TR, Xu Y, Kitzmiller J, Wert SE, Maeda Y, et al. SPDEF is required for mouse pulmonary goblet cell differentiation and regulates a network of genes associated with mucus production. J Clin Invest. 2009; 119(10):2914-24.

Chen G, Volmer AS, Wilkinson KJ, Deng Y, Jones $\mathrm{LC}, \mathrm{Yu} \mathrm{D}$, et al. Role of spdef in the regulation of muc5b expression in the airways of naive and mucoobstructed mice. Am J Respir Cell Mol Biol. 2018;59(3):383-96.

Cibois M, Luxardi G, Chevalier B, Thomé V, Mercey $\mathrm{O}$, Zaragosi LE, et al. BMP signalling controls the construction of vertebrate mucociliary epithelia. Development. 2015;142(13): 2352-63.

Clevers H, Loh KM, Nusse R. An integral program for tissue renewal and regeneration: Wnt signaling and stem cell control. Science. 2014;346(6205):1248012

Collins C, Ventrella R, Mitchell BJ. Building a ciliated epithelium: Transcriptional regulation and radial intercalation of multiciliated cells. In Current Topics in Developmental Biology. Academic Press; 2020.
Corfield AP. Mucins: A biologically relevant glycan barrier in mucosal protection. Biochim Biophys Acta. 2015;1850(1):236-52.

Cutz E, Pan J, Yeger H, Domnik NJ, Fisher JT Recent advances and contraversies on the role of pulmonary neuroepithelial bodies as airway sensors. Semin Cell Dev Biol. 2013;24(1): $40-50$.

Danahay H, Pessotti AD, Coote J, Montgomery BE, Xia D, Wilson A, et al. Notch2 is required for inflammatory cytokine-driven goblet cell metaplasia in the lung. Cell Rep. 2015;10(2): 239-52.

Daniely Y, Liao G, Dixon D, Linnoila RI, Lori A, Randell SH, et al. Critical role of p63 in the development of a normal esophageal and tracheobronchial epithelium. Am J Physiol Cell Physiol. 2004;287(1):C171-81.

Danopoulos S, Shiosaki J, Al Alam D. FGF signaling in lung development and disease: Human versus mouse. Front Genet. 2019;10:170.

Deblandre GA, Wettstein DA, Koyano-nakagawa N, Kintner C. A two-step mechanism generates the spacing pattern of the ciliated cells in the skin of Xenopus embryos. Development. 1999;126(21):4715-28.

Dobzanski A, Khalil SM, Lane AP. Nasal polyp fibroblasts modulate epithelial characteristics via Wnt signaling. Int Forum Allergy Rhinol. 2018;8(12):1412-20.

Doran SA, Koss R, Tran CH, Christopher KJ, Gallin WJ, Goldberg JI. Effect of serotonin on ciliary beating and intracellular calcium concentration in identified populations of embryonic ciliary cells. J Exp Biol. 2004;207(Pt 8):1415-29.

Driskell RR, Liu X, Luo M, Filali M, Zhou W, Abbott $\mathrm{D}$, et al. Wnt-responsive element controls Lef-1 promoter expression during submucosal gland morphogenesis. Am J Physiol Lung Cell Mol Physiol. 2004;287(4):L752-63. 
Driskell RR, Goodheart M, Neff T, Liu X, Luo M, Moothart C, et al. Wnt3a regulates Lef-1 expression during airway submucosal gland morphogenesis. Dev Biol. 2007;305(1):90102.

Dubaissi E. A 'tad' of hope in the fight against airway disease. Biochem Soc Trans. 2020:1-11.

Dubaissi E, Rousseau K, Lea R, Soto X, Nardeosingh S, Schweickert A, et al. A secretory cell type develops alongside multiciliated cells, ionocytes and goblet cells, and provides a protective, anti-infective function in the frog embryonic mucociliary epidermis. Development. 2014;141(7):1514-25.

Dutko JA, Mullins MC. SnapShot: BMP signaling in development. Cell. 2011;145(4):636-2.

Evans CM, Williams OW, Tuvim MJ, Nigam R, Mixides GP, Blackburn MR, et al. Mucin is produced by Clara cells in the proximal airways of antigen-challenged mice. Am J Respir Cell Mol Biol. 2004;31(4):382-94.

Fahy JV, Dickey BF. Airway mucus function and dysfunction. N Engl J Med. 2010;363(23): 2233-47.

Frank DB, Peng T, Zepp JA, Snitow M, Vincent TL, Penkala IJ, et al. Emergence of a wave of Wnt signaling that regulates lung alveologenesis by controlling epithelial self-renewal and differentiation. Cell Rep. 2016;17(9):2312-25.

Giaimo BD, Oswald F, Borggrefe T. Dynamic chromatin regulation at Notch target genes. Transcription. 2017;8(1):61-6.

Goldfarbmuren KC, Jackson ND, Sajuthi SP, Dyjack N, Li KS, Rios CL, et al. Dissecting the cellular specificity of smoking effects and reconstructing lineages in the human airway epithelium. Nat Commun. 2020;11(1):2485.

Gomi K, Arbelaez V, Crystal RG, Walters MS. Activation of NOTCH1 or NOTCH3 signaling skews human airway basal cell differentiation toward a secretory pathway. PLoS One. 2015; 10(2): 0116507.

Gomperts BN, Kim LJ, Flaherty SA, Hackett BP IL-13 regulates cilia loss and foxj1 expression in human airway epithelium. Am J Respir Cell Mol Biol. 2007;37(3):339-46.

Graff JW, Powers LS, Dickson AM, Kim J, Reisetter AC, Hassan IH, et al. Cigarette smoking decreases global microRNA expression in human alveolar macrophages. PLoS One. 2012; 7(8):e44066.

Gurdon JB. The developmental capacity of nuclei taken from intestinal epithelium cells of feeding tadpoles. J Embryol Exp Morphol. 1962; 10:622-40.

Guseh JS, Bores SA, Stanger BZ, Zhou Q, Anderson WJ, Melton DA, et al. Notch signaling promotes airway mucous metaplasia and inhibits alveolar development. Development. 2009;136(10):1751-9.

Haas M, Gómez Vázquez JL, Sun DI, Tran HT, Brislinger $\mathrm{M}$, Tasca $\mathrm{A}$, et al. $\Delta \mathrm{N}-\mathrm{Tp} 63$ mediates $\mathrm{Wnt} / \beta$-catenin-induced inhibition of differentiation in basal stem cells of mucociliary epithelia. Cell Rep. 2019;28(13):3338-e6.
He J, Cai S, Feng H, Cai B, Lin L, Mai Y, et al. Single-cell analysis reveals bronchoalveolar epithelial dysfunction in COVID-19 patients. Protein Cell. 2020;11(9):680-7.

Heijink IH, de Bruin HG, van den Berge M, Bennink LJ, Brandenburg SM, Gosens R, et al. Role of aberrant WNT signalling in the airway epithelial response to cigarette smoke in chronic obstructive pulmonary disease. Thorax. 2013;68(8):709-16.

Henrique D, Schweisguth F. Mechanisms of notch signaling: A simple logic deployed in time and space. Development. 2019;146(3): $\operatorname{dev} 172148$

Hogan BL, Barkauskas CE, Chapman HA, Epstein JA, Jain R, Hsia CC, et al. Repair and regeneration of the respiratory system: complexity, plasticity, and mechanisms of lung stem cell function. Cell Stem Cell. 2014;15(2): 123-38.

Hou Z, Wu Q, Sun X, Chen H, Li Y, Zhang Y, et al. Wnt/Fgf crosstalk is required for the specification of basal cells in the mouse trachea. Development. 2019;146(3):1-6.

Hoyer N, Prior TS, Bendstrup E, Wilcke T, Shaker SB. Risk factors for diagnostic delay in idiopathic pulmonary fibrosis. Respir Res. 2019; 20(1):1-9.

Hu Y, Ng-Blichfeldt JP, Ota C, Ciminieri C, Ren $W$, Hiemstra PS, et al. Wnt $/ \beta$-catenin signaling is critical for regenerative potential of distal lung epithelial progenitor cells in homeostasis and emphysema. Stem Cells.2020; 38(11): 1467-78.

Huang Y, Niehrs C. Polarized Wnt signaling regulates ectodermal cell fate in Xenopus. Dev Cell. 2014;29(2):250-7.

Huang SX, Islam MN, O'Neill J, Hu Z, Yang YG, Chen YW, et al. Efficient generation of lung and airway epithelial cells from human pluripotent stem cells. Nat Biotechnol. 2014; 32(1):84-91.

Huang SX, Green MD, de Carvalho AT, Mumau M, Chen YW, D'Souza SL, et al. The in vitro generation of lung and airway progenitor cells from human pluripotent stem cells. Nat Protoc. 2015;10(3):413-25.

Ibañez-Tallon I, Heintz N, Omran H. To beat or not to beat: roles of cilia in development and disease. Hum Mol Genet. 2003;12 Spec No 1: R27-35.

Kim HT, Yin W, Nakamichi Y, Panza P, Grohmann B, Buettner C, et al. WNT/RYK signaling restricts goblet cell differentiation during lung development and repair. Proc Natl Acad Sci USA. 2019;116(51):25697-706.

Kjolby RAS, Harland RM. Genome-wide identification of $\mathrm{Wnt} / \beta$-catenin transcriptional targets during Xenopus gastrulation. Dev Biol. 2017;426(2):165-75.

König P, Krain B, Krasteva G, Kummer W, Ko P. Serotonin increases cilia-driven particle transport via an acetylcholine-independent pathway in the mouse trachea. PLoS One. 2009;4(3):e4938.
Kurrle Y, Kunesch K, Bogusch S, Schweickert A. Serotonin and MucXS release by small secretory cells depend on Xpod, a SSC specific marker gene. Genesis. 2020;58(2):1-9.

Lafkas D, Shelton A, Chiu C, De Leon Boenig G, Chen Y, Stawicki SS, et al. Therapeutic antibodies reveal Notch control of transdifferentiation in the adult lung. Nature. 2015; 528(7580):127-31.

Lake RJ, Tsai PF, Choi I, Won KJ, Fan HY. RBPJ, the major transcriptional effector of notch signaling, remains associated with chromatin throughout mitosis, suggesting a role in mitotic bookmarking. PLoS Genet. 2014;10(3): e1004204.

Lehmann M, Baarsma HA, Königshoff M. WNT signaling in lung aging and disease. Ann Am Thorac Soc. 2016;13 Suppl 5:S411-6.

Lommel A. Pulmonary neuroendocrine cells (PNEC) and neuroepithelial bodies (NEB): chemoreceptors and regulators of lung development. Paediatr Respir Rev. 2001;2(2):171-

Lynch TJ, Anderson PJ, Rotti PG, Tyler SR, Crooke AK, Choi SH, et al. Submucosal gland myoepithelial cells are reserve stem cells that can regenerate mouse tracheal epithelium. Cell Stem Cell. 2018;22(5):653-e5.

MacDonald BT, Semenov MV, He X. SnapShot: Wnt $/ \beta$-catenin signaling. Cell. 2007;131: 1204-5.

McCormack N, Molloy EL, O'Dea S. Bone morphogenetic proteins enhance an epithelialmesenchymal transition in normal airway epithelial cells during restitution of a disrupted epithelium. Respir Res. 2013;14:36-12.

Méndez A, Rojas DA, Ponce CA, Bustamante R, Beltrán CJ, Toledo J, et al. Primary infection by Pneumocystis induces Notch-independent Clara cell mucin production in rat distal airways. PLoS One. 2019;14(6):e0217684-18.

Merrell AJ, Stanger BZ. Adult cell plasticity in vivo: De-differentiation and transdifferentiation are back in style. Nat Rev Mol Cell Biol. 2016;17(7):413-25.

Meunier A, Azimzadeh J. Multiciliated cells in animals. Cold Spring Harb Perspect Biol. 2016;8(12):a028233.

Mitchison HM, Valente EM. Motile and non-motile cilia in human pathology: from function to phenotypes. J Pathol. 2017;241(2):294309 .

Molloy E, Adams A, Moore JB, Masterson J, Madrigal-Estebas L, Mahon B, et al. BMP4 induces an epithelial-mesenchymal transition-like response in adult airway epithelial cells. Growth Factors. 2008;26(1):12-22.

Montoro DT, Haber AL, Biton M, Vinarsky V, Lin B, Birket SE, et al. A revised airway epithelial hierarchy includes CFTR-expressing ionocytes. Nature. 2018;560(7718):319-24.

Morimoto M, Nishinakamura R, Saga Y, Kopan R. Different assemblies of Notch receptors coordinate the distribution of the major bronchial Clara, ciliated and neuroendocrine cells. Development. 2012;139(23):4365-73. 
Mou H, Vinarsky V, Tata PR, Brazauskas K, Choi $\mathrm{SH}$, Crooke AK, et al. Dual SMAD signaling inhibition enables long-term expansion of diverse epithelial basal cells. Cell Stem Cell. 2016;19(2):217-31.

Mucenski ML, Nation JM, Thitoff AR, Besnard V, $\mathrm{Xu} \mathrm{Y}$, Wert SE, et al. Beta-catenin regulates differentiation of respiratory epithelial cells in vivo. Am J Physiol Lung Cell Mol Physiol. 2005;289(6):L971-9.

Mukherjee AB, Zhang Z, Chilton BS. Uteroglobin: A steroid-inducible immunomodulatory protein that founded the Secretoglobin superfamily. Endocr Rev. 2007;28(7):707-25.

Naylor S, Chen JY. Unraveling human complexity and disease with systems biology and personalized medicine. Per Med. 2010;7(3):27589.

Nishikawa S, Hirata J, Sasaki F. Fate of ciliated epidermal cells during early development of Xenopus laevis using whole-mount immunostaining with an antibody against chondroitin 6-sulfate proteoglycan and anti-tubulin: transdifferentiation or metaplasia of amphibian epidermis. Histochemistry. 1992; 98(6):355-8.

Pardo-Saganta A, Law BM, Gonzalez-Celeiro M, Vinarsky V, Rajagopal J. Ciliated cells of pseudostratified airway epithelium do not become mucous cells after ovalbumin challenge. Am J Respir Cell Mol Biol. 2013;48(3):364-73.

Pardo-Saganta A, Law BM, Tata PR, Villoria J, Saez B, Mou H, et al. Injury induces direct lineage segregation of functionally distinct airway basal stem/progenitor cell subpopulations. Cell Stem Cell. 2015a;16(2):184-97.

Pardo-Saganta A, Tata PR, Law BM, Saez B, Chow $\mathrm{RD}$, Prabhu M, et al. Parent stem cells can serve as niches for their daughter cells. Nature. 2015b;523(7562):597-601.

Parker JC, Thavagnanam S, Skibinski G, Lyons J, Bell J, Heaney LG, et al. Chronic IL9 and IL-13 exposure leads to an altered differentiation of ciliated cells in a well-differentiated paediatric bronchial epithelial cell model. PLoS One. 2013;8(5):e61023.

Peng T, Frank DB, Kadzik RS, Morley MP, Rathi KS, Wang T, et al. Hedgehog actively maintains adult lung quiescence and regulates repair and regeneration. Nature. 2015; 526(7574):578-82.

Perrimon N, Pitsouli C, Shilo BZ. Signaling mechanisms controlling cell fate and embryonic patterning. Cold Spring Harb Perspect Biol. 2012;4(8):a005975.

Plasschaert LW, Žilionis R, Choo-Wing R, Savova V, Knehr J, Roma G, et al. A single-cell atlas of the airway epithelium reveals the CFTRrich pulmonary ionocyte. Nature. 2018; 560(7718):377-81.

Quigley IK, Kintner C. Rfx2 stabilizes Foxj1 binding at chromatin loops to enable multiciliated cell gene expression. PLoS Genet. 2017;13(1): e1006538-29.

Quigley IK, Stubbs JL, Kintner C. Specification of ion transport cells in the Xenopus larval skin. Development. 2011;138(4):705-14.
Rawlins EL, Okubo T, Xue Y, Brass DM, Auten RL, Hasegawa H, et al. The Role of Scgbla1+ Clara cells in the long-term maintenance and repair of lung airway, but not alveolar, epithelium. Cell Stem Cell. 2009;4(6):525-34.

Renz H, Autenrieth IB, Brandtzæg P, Cookson WO, Holgate S, Von Mutius E, et al. Geneenvironment interaction in chronic disease: $\mathrm{A}$ European Science Foundation forward look. J Allergy Clin Immunol. 2011;128(6 Suppl 1): S27-49.

Reynolds SD, Malkinson AM. Clara cell: Progenitor for the bronchiolar epithelium. Int J Biochem Cell Biol. 2010;42(1):1-4.

Reynolds SD, Zemke AC, Giangreco A, Brockway BL, Teisanu RM, Drake JA, et al. Conditional stabilization of beta-catenin expands the pool of lung stem cells. Stem Cells. 2008;26(5): 1337-46.

Rock JR, Onaitis MW, Rawlins EL, Lu Y, Clark $\mathrm{CP}$, Xue Y, et al. Basal cells as stem cells of the mouse trachea and human airway epithelium. Proc Natl Acad Sci USA. 2009;106(31): 12771-5.

Rock JR, Randell SH, Hogan BL. Airway basal stem cells: a perspective on their roles in epithelial homeostasis and remodeling. Dis Model Mech. 2010;3(9凶10):545-56.

Rock JR, Gao X, Xue Y, Randell SH, Kong YY, Hogan BL. Notch-dependent differentiation of adult airway basal stem cells. Cell Stem Cell. 2011;8(6):639-48.

Rokicki W, Rokicki M, Wojtacha J, Dżeljijli A. The role and importance of club cells (Clara cells) in the pathogenesis of some respiratory diseases. Kardiochir Torakochirurgia Pol. 2016;13(1):26-30.

Roy $\mathrm{S}$. The motile cilium in development and disease: emerging new insights. Bioessays. 2009; 31(7):694-9.

Ruiz García S, Deprez M, Lebrigand K, Cavard A, Paquet A, Arguel MJ, et al. Novel dynamics of human mucociliary differentiation revealed by single-cell RNA sequencing of nasal epithelial cultures. Development. 2019;146(20). dev. 177428

Ruptier C, De Gaspéris A, Ansieau S, Granjon A, Tanière $\mathrm{P}$, Lafosse I, et al. TP63 $\mathrm{P} 2$ promoter functional analysis identifies $\beta$-catenin as a key regulator of $\triangle \mathrm{Np} 63$ expression. Oncogene. 2011;30(46):4656-65.

Sanz-Ezquerro JJ, Münsterberg AE, Stricker S. Editorial: Signaling pathways in embryonic development. Front Cell Dev Biol. 2017;5:76-3.

Schamberger AC, Mise N, Jia J, Genoyer E, Yildirim AÖ, Meiners S, et al. Cigarette smoke-induced disruption of bronchial epithelial tight junctions is prevented by transforming growth factor- $\beta$. Am J Respir Cell Mol Biol, 2014;50(6):1040-52.

Schamberger AC, Staab-Weijnitz CA, MiseRacek N, Eickelberg O. Cigarette smoke alters primary human bronchial epithelial cell differentiation at the air-liquid interface. Sci Rep. 2015;5:8163-9.
Schmid A, Sailland J, Novak L, Baumlin N, Fregien N, Salathe M. Modulation of Wnt signaling is essential for the differentiation of ciliated epithelial cells in human airways. FEBS Lett. 2017;591(21):3493-506.

Sears ME, Genuis SJ. Environmental determinants of chronic disease and medical approaches: Recognition, avoidance, supportive therapy, and detoxification. J Environ Public Health. 2012;2012:356798.

Semenov MV, Habas R, Macdonald BT, He X. SnapShot: Noncanonical Wnt signaling pathways. Cell. 2007;131(7):1378.

Senoo M, Pinto F, Crum CP, McKeon F. p63 is essential for the proliferative potential of stem cells in stratified epithelia. Cell. 2007;129(3): 523-36.

Shi J, Li F, Luo M, Wei J, Liu X. Distinct roles of $\mathrm{Wnt} / \beta$-catenin signaling in the pathogenesis of chronic obstructive pulmonary disease and idiopathic pulmonary fibrosis. Mediators Inflamm. 2017;2017:3520581.

Sirour C, Hidalgo M, Bello V, Buisson N, Darribère T, Moreau N. Dystroglycan is involved in skin morphogenesis downstream of the Notch signaling pathway. Mol Biol Cell. 2011; 22(16):2957-69.

Smith CR. Diagnosis in chronic obstructive pulmonary disease -- "too little, too late? Chron Respir Dis. 2015;12(4):281-3.

Sountoulidis A, Stavropoulos A, Giaglis S, Apostolou E, Monteiro R, Chuva de Sousa Lopes $\mathrm{SM}$, et al. Activation of the canonical bone morphogenetic protein (BMP) pathway during lung morphogenesis and adult lung tissue repair. PLoS One. 2012;7(8):e41460.

Steinhart Z, Angers S. Wnt signaling in development and tissue homeostasis. Development. 2018;145(11):dev146589.

Stubbs JL, Davidson L, Keller R, Kintner C. Radial intercalation of ciliated cells during Xenopus skin development. Development. 2006; 133(13):2507-15.

Sun DI, Tasca A, Haas M, Baltazar G, Harland $\mathrm{RM}$, Finkbeiner WE, et al. $\mathrm{Na}+/ \mathrm{H}+$ exchangers are required for the development and function of vertebrate mucociliary epithelia. Cells Tissues Organs. 2018;205(5区6):279-92.

Tadokoro T, Gao X, Hong CC, Hotten D, Hogan BL. BMP signaling and cellular dynamics during regeneration of airway epithelium from basal progenitors. Development. 2016;143(5): 764-73.

Takahashi K, Yamanaka S. Induction of pluripotent stem cells from mouse embryonic and adult fibroblast cultures by defined factors. Cell. 2006;126(4):663-76.

Tasca A, Helmstädter M, Brislinger M, Haas M, Mitchell BJ, Walentek P. Notch signaling induces either apoptosis or cell fate change in multiciliated cells during mucociliary tissue remodeling. Dev Cell. 2021;56(4):525-39.

Tata PR, Rajagopal J. Plasticity in the lung: Making and breaking cell identity. Development. 2017;144(5):755-66. 
Tata PR, Mou H, Pardo-Saganta A, Zhao R, Prabhu M, Law BM, et al. Dedifferentiation of committed epithelial cells into stem cells in vivo. Nature. 2013;503(7475):218-23.

Tilley AE, Harvey BG, Heguy A, Hackett NR, Wang R, O'Connor TP, et al. Down-regulation of the notch pathway in human airway epithelium in association with smoking and chronic obstructive pulmonary disease. Am J Respir Crit Care Med. 2009;179(6):457-66.

Tilley AE, Walters MS, Shaykhiev R, Crystal RG. Cilia dysfunction in lung disease. Annu Rev Physiol. 2015;77:379-406.

Tsao PN, Vasconcelos M, Izvolsky KI, Qian J, Lu J, Cardoso WV. Notch signaling controls the balance of ciliated and secretory cell fates in developing airways. Development. 2009; 136(13):2297-307.

Turner J, Roger J, Fitau J, Combe D, Giddings J, Heeke GV, et al. Goblet cells are derived from a FOXJ1-expressing progenitor in a human airway epithelium. Am J Respir Cell Mol Biol. 2011;44(3):276-84.

Tyner JW, Kim EY, Ide K, Pelletier MR, Roswit WT, Morton JD, et al. Blocking airway mucous cell metaplasia by inhibiting EGFR antiapoptosis and IL-13 transdifferentiation signals. J Clin Invest. 2006;116(2):309-21.

Rijt SH, Keller IE, John G, Kohse K, Yildirim AÖ, Eickelberg $\mathrm{O}$, et al. Acute cigarette smoke exposure impairs proteasome function in the lung. Am J Physiol Lung Cell Mol Physiol. 2012;303(9):L814-L823.

Vladar EK, Axelrod JD. Dishevelled links basal body docking and orientation in ciliated epithelial cells. Trends Cell Biol. 2008;18(11): 517-20.

Vladar EK, Königshoff M. Noncanonical Wnt planar cell polarity signaling in lung development and disease. Biochem Soc Trans. 2020; 48(1):231-43.

Wagner CE, Wheeler KM, Ribbeck K. Mucins and their role in shaping the functions of $\mathrm{mu}-$ cus barriers. Annu Rev Cell Dev Biol. 2018;34: 189-215.

Walentek P. Manipulating and analyzing cell type composition of the Xenopus mucociliary epidermis. Methods Mol Biol. 2018;1865:25163.
Walentek P, Quigley IK. What we can learn from a tadpole about ciliopathies and airway diseases: Using systems biology in Xenopus to study cilia and mucociliary epithelia. Genesis. 2017;55(1-2):1-13.

Walentek P, Boutin C, Kodjabachian L. Planar cell polarity in ciliated epithelia. In: Houston $\mathrm{D}$ (ed). Cell Polarity in Development and Disease. Elsevier; 2017. p. 177-209.

Walentek P, Beyer T, Thumberger T, Schweickert A, Blum M. ATP4a is required for Wnt-dependent Foxj1 expression and leftward flow in Xenopus left-right development. Cell Rep. 2012;1(5):516-27.

Walentek P, Bogusch S, Thumberger T, Vick P, Dubaissi E, Beyer T, et al. A novel serotoninsecreting cell type regulates ciliary motility in the mucociliary epidermis of Xenopus tadpoles. Development. 2014;141(7):1526-33.

Walentek P, Beyer T, Hagenlocher C, Müller C, Feistel K, Schweickert A, et al. ATP4a is required for development and function of the Xenopus mucociliary epidermis - a potential model to study proton pump inhibitor-associated pneumonia. Dev Biol. 2015;408(2): 292-304.

Wallingford JB. Planar cell polarity signaling, cilia and polarized ciliary beating. Curr Opin Cell Biol. 2010;22(5):597-604.

Walters MS, Gomi K, Ashbridge B, Moore MA, Arbelaez V, Heldrich J, et al. Generation of a human airway epithelium derived basal cell line with multipotent differentiation capacity. Respir Res. 2013;14:135.

Wang R, Ahmed J, Wang G, Hassan I, StruloviciBarel Y, Hackett NR, et al. Down-regulation of the canonical Wnt $\beta$-catenin pathway in the airway epithelium of healthy smokers and smokers with COPD. PLoS One. 2011;6(4): e14793.

Wang Y, Liu J, Zhou JS, Huang HQ, Li ZY, Xu XC, et al. MTOR suppresses cigarette smoke-induced epithelial cell death and airway inflammation in chronic obstructive pulmonary disease. J Immunol. 2018;200(8):2571-80.

Wang X, Xu C, Ji J, Cai Y, Shu Y, Chao Y, et al. IL-4/IL-13 upregulates Sonic hedgehog expression to induce allergic airway epithelial remodeling. Am J Physiol Lung Cell Mol Physiol. 2020;318(5):L888-99.

Wells JM, Watt FM. Diverse mechanisms for endogenous regeneration and repair in mammalian organs. Nature. 2018;557(7705): 322-8.
Weng G, Bhalla US, Iyengar R. Complexity in biological signaling systems. Science. 1999; 284(5411):92-6.

Williams OW, Sharafkhaneh A, Kim V, Dickey BF, Evans CM. Airway mucus: From production to secretion. Am J Respir Cell Mol Biol. 2006;34(5):527-36.

Xie W, Lynch TJ, Liu X, Tyler SR, Yu S, Zhou X, et al. Sox 2 modulates Lef- 1 expression during airway submucosal gland development. Am J Physiol Lung Cell Mol Physiol. 2014;306(7): L645-60.

Yu H, Li Q, Kolosov VP, Perelman JM, Zhou X. Interleukin-13 induces mucin $5 \mathrm{AC}$ production involving STAT6/SPDEF in human airway epithelial cells. Cell Commun Adhes. 2011;17(4-6):83-92.

Yuan T, Volckaert T, Chanda D, Thannickal VJ, De Langhe SP. Fgf10 signaling in lung development, homeostasis, disease, and repair after injury. Front Genet. 2018;9:1-8.

Zanin M, Baviskar P, Webster R, Webby R. The interaction between respiratory pathogens and mucus. Cell Host Microbe. 2016;19(2): 159-68.

Zariwala MA, Omran H, Ferkol TW. The emerging genetics of primary ciliary dyskinesia. Proc Am Thorac Soc. 2011;8(5):430-3.

Zemke AC, Teisanu RM, Giangreco A, Drake JA, Brockway BL, Reynolds SD, et al. betaCatenin is not necessary for maintenance or repair of the bronchiolar epithelium. Am J Respir Cell Mol Biol. 2009;41(5):535-43.

Zhang L, Gallup M, Zlock L, Chen YT, Finkbeiner WE, McNamara NA. Pivotal role of MUC1 glycosylation by cigarette smoke in modulating disruption of airway adherens junctions in vitro. J Pathol. 2014;234(1):60-73.

Zuo W, Zhang T, Wu DZ, Guan SP, Liew AA, Yamamoto Y, et al. p63(+)Krt5(+) distal airway stem cells are essential for lung regeneration. Nature. 2015;517(7536):616-20.

Zuo WL, Yang J, Strulovici-Barel Y, Salit J, Rostami M, Mezey JG, et al. Exaggerated BMP4 signalling alters human airway basal progenitor cell differentiation to cigarette smokingrelated phenotypes. Eur Respir J. 2019;53(5): 1702553.

Zuo WL, Rostami MR, LeBlanc M, Kaner RJ, O’Beirne SL, Mezey JG, et al. Dysregulation of club cell biology in idiopathic pulmonary fibrosis. PLoS One. 2020;15:e0237529. 